Document downloaded from:

http://hdl.handle.net/10251/148902

This paper must be cited as:

Desantes, J.; López, JJ.; García-Oliver, JM.; López-Pintor, D. (2017). Experimental validation and analysis of seven different chemical kinetic mechanisms for $n$-dodecane using a Rapid Compression-Expansion Machine. Combustion and Flame. 182:76-89. https://doi.org/10.1016/j.combustflame.2017.04.004

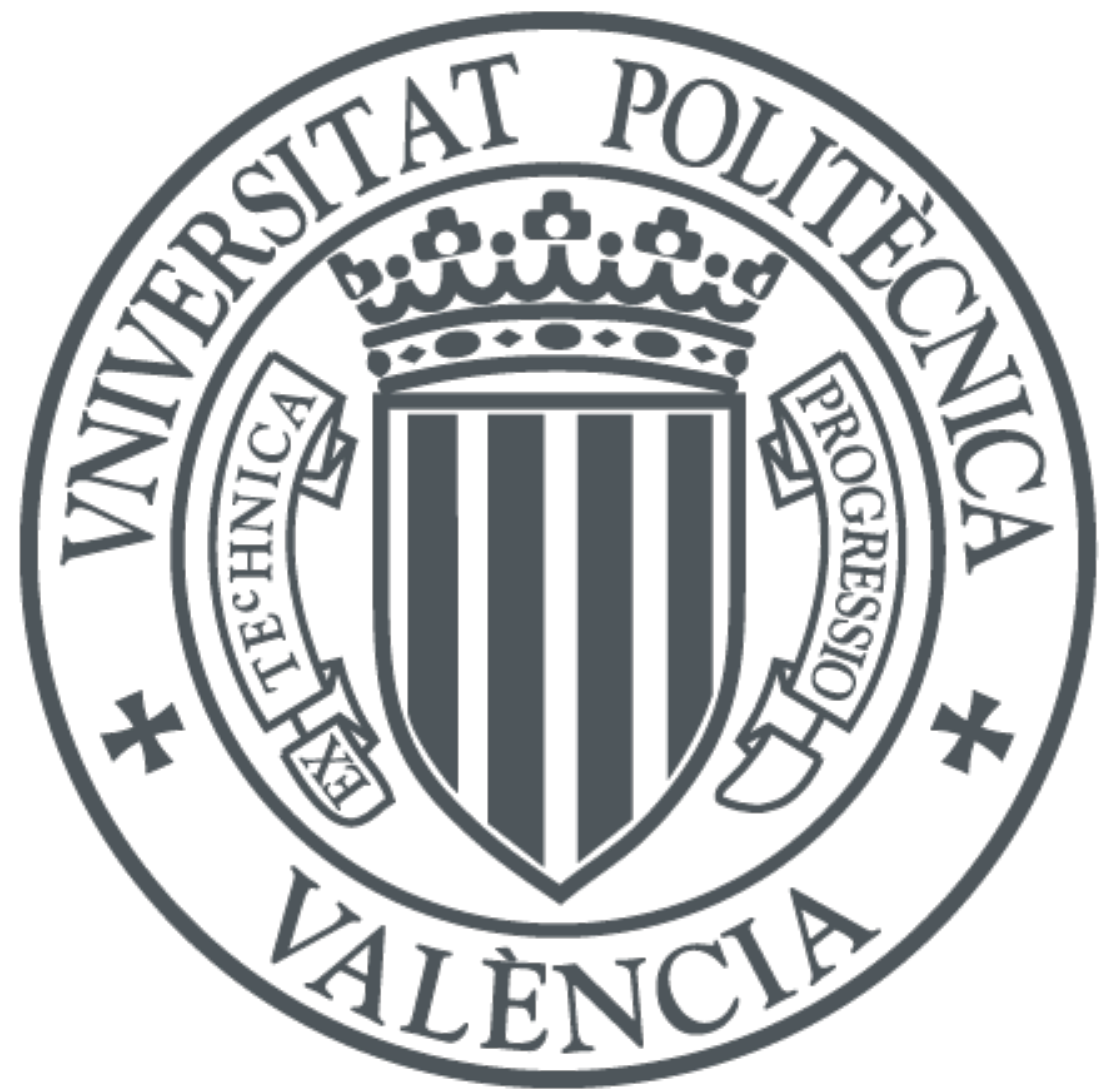

The final publication is available at

https://doi.org/10.1016/j.combustflame.2017.04.004

Copyright Elsevier

Additional Information 


\title{
Experimental validation and analysis of seven different chemical kinetic mechanisms for n-dodecane using a Rapid Compression-Expansion Machine
}

\author{
José M. Desantes ${ }^{\mathrm{a}}$, J. Javier López ${ }^{\mathrm{a}, *}$, José M. García-Olivera ${ }^{\mathrm{a}}$, Darío \\ López-Pintor ${ }^{\mathrm{a}}$ \\ ${ }^{a}$ CMT-Motores Térmicos \\ Universitat Politècnica de València \\ Camino de Vera, s/n. 46022 Valencia, SPAIN
}

\begin{abstract}
Seven different chemical kinetic mechanisms for n-dodecane, two detailed and five reduced, have been evaluated under Engine Combustion Network (ECN) thermodynamic conditions by comparison to experimental measurements in a Rapid Compression-Expansion Machine (RCEM). The target ECN conditions are imposed at Top Dead Center (TDC), which cover a wide range of temperatures (from $850 K$ to $1000 K$ ), oxygen molar fractions ( 0.21 and $0.15)$ and equivalence ratios $(0.8,0.9$ and 1$)$, while the pressure is fixed to keep a constant density at TDC equal to $22.8 \mathrm{~kg} / \mathrm{m}^{3}$. The results obtained have been used to validate the chemical kinetic simulations, which have been performed with CHEMKIN, by comparing both cool flames and high temperature ignition delays, as well as the heat released in each stage of the combustion process in case of having a two-stage ignition pattern. The experimental results show good agreement with the chemical kinetic simulations. In fact,
\end{abstract}

\footnotetext{
${ }^{*}$ Corresponding author Tel: +34963 879 232. Fax: +34963877659. E-mail: jolosan3@mot.upv.es
} 
the mean relative deviation in ignition delay between experiments and simulations among all the chemical mechanisms is equal to $18.0 \%(3 C A D)$ for both cool flames and high temperature ignition. In general, closer correspondence has been obtained for the ignition delay referred to the high-temperature stage of the process, being the cool flames phenomenon more difficult to reproduce. Moreover, the differences between the reduced mechanisms and the most detailed one have been analyzed, concluding that the enhanced specific reaction rates of the most reduced mechanisms cause differences not only on the ignition delays, but also on the Negative Temperature Coefficient (NTC) behavior and on the heat released during cool flames.

Keywords: RCEM, ignition delay, autoignition modeling, ECN, n-dodecane

\section{Introduction, justification and objective}

The Engine Combustion Network (ECN) is a worldwide group of institu3 tions in which an experimental and modeling collaboration dedicated to the 4 improvement of the spray and combustion knowledge under engine conditions 5 is performed. The ECN database is composed by quantitative information 6 about reacting and non-reacting sprays, including spray characteristics re7 lated to evaporation and mixing, such as the liquid and vapor penetration lengths or the spray angle, as well as other characteristics related to combustion, such as the lift-off length or the ignition delay. These data are usually obtained from combustion vessels under fully-controlled high-temperature and high-pressure conditions, providing high-quality information for the improvement of Computational Fluid Dynamics (CFD) models under realistic 
engine conditions. For instance, some contributions to the ECN experimental database have been performed by Pickett et al. [1] or Malbec et al. [2], while the use of such database for model validation can be seen in the works of Pei et al. [3] or Novella et al. [4].

A current topic at ECN is the analysis of the effects of using different chemical kinetic mechanisms in CFD applications [5]. Although ignition can be properly simulated by means of advanced CFD codes coupled to detailed chemistry, the required computing time can be too long, since the conservation of species equations for all the species involved in the mechanism have to be solved for each cell of the domain. This is the reason why the higher the spatial resolution, the simpler the chemical mechanism employed to solve the reaction paths, i.e., the use of detailed chemical kinetic mechanisms coupled to CFD codes is limited by the physical discretization of the domain. Thus, the computational cost of solving detailed chemistry in cases with a high number of cells could be unacceptable, imposing the use of reduced mechanisms.

The reduction of a chemical kinetic mechanism can be performed following different strategies [6], as e.g. principal component analysis [7], sensitivity analysis [8], Jacobian analysis [9], detailed reduction [10], directed relation graph (DRG) [11] or path flux analysis [12], among others. An evaluation of the skeletal mechanism accuracy relative to that of the original one has great interest as a method to analyze the mechanism reduction process. It should be noted that the more complex the hydrocarbon, the higher the number of species and reactions needed to describe its oxidation. For instance, one of the most detailed mechanisms to describe the n-dodecane oxidation has been 
developed by Lawrence Livermore National Laboratory (LLNL) [13], and it is composed by 2885 species and 11754 reactions. However, it is important to note that even detailed chemical kinetic mechanisms have to be validated by comparison to experimental results over a wide range of temperatures, pressures and equivalence ratios. This detailed chemical kinetic mechanism has been reduced by several authors in order to obtain skeletal mechanisms that can be more easily coupled to CFD codes to perform spray simulations in the frame of the ECN, where n-dodecane is the standard fuel.

Lu et al. [14] reduced the detailed mechanism for n-dodecane from LLNL using a combination of a DRG with expert knowledge (DRG-X) method and a DRG combined with sensitivity analysis (DRGASA), both coupled with isomer lumping. The resulting mechanism is composed by 163 species and 887 reactions. The DRG-X method tries to reduce a give mechanism paying attention to a given combustion parameter that is intended to be correctly predicted. To do so, the main chemical paths, as well as the corresponding more relevant species are identified. Thus, high accuracy is imposed for the relevant species while higher errors are allowed for the other species. This reduced mechanism has been successfully applied to CFD spray simulations. However, experimental validation under homogeneous conditions should be performed to decouple the accuracy of the CFD models from the accuracy of the mechanism itself.

Luo et al. [15] developed a skeletal mechanism for n-dodecane with 105 species and 420 reactions, specially adjusted for spray combustion simulations. An algorithm combining DRG-X and sensitivity analysis was employed for the reduction. The skeletal mechanism was validated by comparison to 
the detailed one according to autoignition characteristics, jet stirred reactor results, laminar premixed flame velocities and diffusion flame velocities. Moreover, an additional validation was performed in CFD spray combustion simulations under engine conditions. However, a wide experimental validation under homogeneous conditions, where the chemical kinetics can be traced, for high pressures as the ones reached in diesel engines is needed.

Narayanaswamy et al. [16] proposed a reduced chemical kinetic mechanism composed by 225 species and 1509 reactions that describes the oxidation of n-dodecane. Despite the fact that the skeletal mechanism includes both the low and high-temperature oxidation paths, which are based on [13] and [17] respectively, some specific reaction rates were changed to improve the calculations. Besides, this mechanism also includes aromatic chemistry from [18]. A wide validation has been performed by comparison to experimental data from shock tubes, rapid compression machines, pressurized flow reactors and burners; and not only according to ignition delays, but also according to species concentrations and burning velocities. However, most of this extensive validation was carried out at low pressures (from 7 bar to 40 bar), and an extension to ECN conditions $(\mathrm{P} \approx 60$ bar $)$ can be interesting.

Wang et al. [19] proposed a skeletal chemical kinetic mechanism for ndodecane composed by 100 species and 432 reactions, which was reduced from the archived detailed mechanism for n-alkanes developed by the LLNL [20]. The mechanism includes a PAH sub-mechanism for soot production and oxidation and it was compared with the optical measurements carried out in a constant volume vessel from the ECN by coupling the mechanism with a soot model. Simulations can reproduce the main trends of the soot 
formation process. However, unsuccessful comparisons versus a reference n-heptane mechanism [21] show that the n-dodecane mechanism tends to predict shorter ignition delays under spray combustion conditions, although the predicted ignition delays of n-heptane are very close (or even shorter) to the values for n-dodecane under homogeneous conditions, which is non-sense. Therefore, chemical kinetic mechanisms should be continuously improved, specially those that describe such a long chain hydrocarbon as n-dodecane.

Yao et al. [22] developed a skeletal mechanism with 54 species and 269 reactions to predict the n-dodecane oxidation. The mechanism was reduced from the more detailed mechanism of You et al. [23] by means of reaction flow analysis, sensitivity analysis and isomer lumping methods. The resulting reactions have been combined with San Diego's mechanism [24] to generate a block of reactions for the high-temperature oxidation paths. The lowtemperature branching was described by semi-global reactions from Bikas and Peters [25], the specific reaction rates of which were tuned according to ignition delay calcualtions by comparison to the detailed mechanism from LLNL [13] and experimental data from a shock tube at 20 bar. Besides, an additional comparison and tuning respect to n-decane ignition delays at 50 bar was performed. However, tuning the low-temperature branching mechanism of n-dodecane by using the ignition characteristics of $n$-decane at high pressures can lead to improper results. Thus, an evaluation of the reduced mechanism by comparing to n-dodecane ignition delays under highpressure conditions should be done.

Finally, Cai et al. [26] developed a detailed chemical kinetic mechanism for n-dodecane based on the LLNL mechanism [13], which was modified ac- 
cording to the improvements on the low-temperature oxidation kinetics proposed by Bugler et al. [27]. On the one hand, the rate rules were replaced according to the work of Bugler et al. and specific reaction rates for $\mathrm{H}$-atom abstractions from the fuel by $\mathrm{OH}$ radicals were modified according to the work of Sivaramakrishnan and Michael [28]. On the other hand, alternative reaction pathways for the low-temperature chain branching mechanism were incorporated. The resulting mechanism consist of 1692 species and 5804 reactions and it has been widely validated by comparison to experimental measurements.

It should be noted that, while the first three reduced mechanisms described are based on the most recent version of the n-alkanes detailed mechanism from LLNL (from $\mathrm{C}_{7}$ to $\mathrm{C}_{20}$ ), Wang's and Yao's mechanisms are based on different detailed versions. The reduced mechanism proposed by Wang et al. is based on an archived mechanism that was validated by modeling and experimental comparisons under a wide range of pressure (from 1 bar to $80 \mathrm{bar}$ ), temperatures (from $650 \mathrm{~K}$ to $1600 \mathrm{~K}$ ), equivalence ratios (from 0.2 to 1.5 ) and oxygen volume fractions (from $0 \%-99.6 \%$ in Ar- to $21 \%$ ). However, there are some gaps in the experimental database, specially for long chain n-alkanes (including n-dodecane). Thus, it would be advisable to perform some complementary measurements for the validation under ECN conditions. Besides, the skeletal mechanism proposed by Yao et al. was based on a mechanism composed by 171 species and 1306 reactions, which is not as detailed as the one proposed by LLNL. Moreover, the low-temperature paths are described by semi-global reactions in the skeletal mechanism, which were tuned versus experimental data of n-decane at high pressures, requiring an 
additional validation for $\mathrm{n}$-dodecane.

The five reduced mechanisms presented in the previous paragraphs have been coupled to CFD codes in the frame of the ECN for the calculation of reactive spray characteristics. However, Hawkes [5] showed that different mechanisms lead to different ignition delays. Specifically, Luo's and Narayanaswamy's mechanisms seems to over-predict the ignition delay in spray ignition studies, while Yao's mechanism shows an extremely good accuracy for spray A studies. In fact, the problem could arise from the description of the chemistry paths. According to shock-tube data in engine-relevant conditions (specifically, having a pressure of 50 bar ans equivalence ratio of $0.5,1$ and 2 [20,29]), Luo's and Narayanaswamy's mechanisms seem to over-predict the ignition delay at low temperatures (approximately less than $900 \mathrm{~K}$ ), while Yao's highly under-predicts the ignition delay at intermediate temperatures (approximately between $750 \mathrm{~K}$ and $1000 \mathrm{~K}$ ). Thus, two motivations can be determined from the last ECN workshop: the generation of a wide database of ignition delays for n-dodecane under (or similar to) ECN conditions, and the understanding of the differences in the ignition process when different mechanisms are used.

Several experimental data for the ignition delay of n-dodecane under constant conditions can be found in the literature. For instance, Shen et al. [30] studied the ignition of n-heptane, n-decane, n-dodecane and n-tetradecane in a shock tube by measuring the ignition delay before the reflected shock wave. Fuel/air mixtures with equivalence ratios equal to $0.25,0.5$ and 1.0 were tested at pressures from 9 to $58 \mathrm{~atm}$ and temperatures form 786 to $1396 \mathrm{~K}$. However, it should be noted that, as far as the authors know, there 
are no experimental results available for the auto-ignition of n-dodecane under engine conditions, i.e., in a controlled compression and expansion stroke as the ones performed in a RCEM, which justifies this investigation.

The RCEM used in this investigation works as an HCCI engine. Thus, some stratification effects are expected due to wall effects and heat losses. Thermal stratification under HCCI conditions affects the heat release rate by increasing the combustion duration. Thus, a sequential autoignition is established in the combustion chamber, leading to a progressive heat release. Furthermore, thermal stratification can affect also the ignition delay because of the interaction between cold and hot zones and not only during the ignition delay time, but also during the combustion event. Thus, a proper ignition delay definition based on the first stage of the heat release is critical under these conditions. Several experimental and simulation works have been performed about the thermal stratification in autoignition studies. For instance, Sjöberg et al. [31] studied the role of the natural thermal stratification on the combustion duration and on the pressure rise rate experimentally in an HCCI engine and by simulation solving a multi-zone model in CHEMKIN. The authors found that natural thermal stratification generated by heat losses can explain the progressive pressure rise that is typical of this combustion mode. Moreover, Chen et al. [32] studied the effect of thermal stratification on $\mathrm{H}_{2}$ autoignition by means of direct numerical simulations. The authors found that autoignition propagation seems to be inversely proportional to $\nabla T$ for medium-to-low temperature gradients, while diffusive effects become relevant when $\nabla T$ increases. Besides, the ignition delay seems to be governed by the competition between accumulation of chain carriers and diffusion in the dif- 
ferent zones of the combustion chamber. Thus, Chen et al. demonstrated that heterogeneities affects not only the heat release, but also the initial ignition delay. Finally, Yoo et al. [33] studied the sequential autoignition of n-heptane by thermal stratification using direct numerical simulations. The authors showed that the ignition delay behavior with the temperature fluctuations changes depending on the mean temperature value and the NTC regime of the fuel. Thus, if fluctuations are increased, the ignition delay increases for a mean temperature lower than the NTC zone, while it decreased for a mean temperature higher than the NTC zone. For a mean temperature value within the NTC zone the ignition delay increases for small fluctuations but it decreased for large fluctuations. Furthermore, Yoo et al. also studied the effects of the turbulence timescale on the ignition. Thus, fast turbulence timescale homogenizes the mixture leading to a faster ignition propagation, while longer turbulence timescales are not able to homogenize the temperature and the ignition propagation occurs mainly by deflagration. However, the effect of the turbulence timescales on the ignition delay is almost negligible compared to that of thermal stratification.

The validity of the previously described seven chemical kinetic mechanisms, two detailed and five reduced, to determine both high-temperature and cool flames ignition delays under ECN conditions is intended to be investigated in the present work. The study has been done with n-dodecane, which is the reference fuel at ECN. The accuracy of the different mechanisms according to ignition delay has been analyzed by comparison with the results of a parametric study performed in a RCEM. To do so, a wide database of ignition delays under engine conditions have been generated. Besides, the 
differences between mechanisms have been analyzed from a chemical kinetic point of view. Simulations have been performed with the software of chemical simulation CHEMKIN, which is developed by Reaction Design (ANSYS).

The structure of the paper is the following: first, the experimental facility involved in the study is presented. Then, the methodological approach is described, including the parametric study performed, the experimental methods and the chemical kinetic simulations. Afterwards, the experimental ignition delays are analyzed, the chemical kinetic mechanisms are validated with the experimental results and the reduced mechanisms are compared to the detailed ones. Finally, the conclusions of this study are shown.

\section{Experimental facility}

The RCEM used in this work is an experimental facility widely described in other previous papers, such as [34-36]. Therefore, only the main technical characteristics of the facility are described in this section, a full description being available in the previously mentioned references.

\begin{tabular}{|l|ll|}
\hline Bore & 84 & $\mathrm{~mm}$ \\
\hline Stroke & $120-249$ & $\mathrm{~mm}$ \\
\hline Compression ratio & $5-30$ & - \\
\hline Maximum cylinder pressure & 200 & bar \\
\hline Initial pressure & $1-5$ & bar \\
\hline Maximum heating temperature & 473 & $\mathrm{~K}$ \\
\hline
\end{tabular}

Table 1: Technical characteristics of the RCEM.

The main technical characteristics of the RCEM are shown in Table 1. As 
it can be seen, different compression ratios are available by varying the stroke and the clearance volume. Moreover, the compression velocity can be varied by changing the driving gas pressure in order to simulate different engine speeds. It should be noted that most of the expansion stroke of the piston can be also analyzed in the RCEM, so that a full combustion diagnosis can be performed. Furthermore, the experimentation piston, which is $84 \mathrm{~mm}$ in bore and that includes a $46 \mathrm{~mm}$ in bore and $17 \mathrm{~mm}$ in depth cylindrical bowl, is coupled to an AMO LMK102 incremental position sensor with $0.01 \mathrm{~mm}$ of resolution.

The walls temperature is controlled by a $80 \mathrm{~W}$ heater located in the bowl, and two more spire-shape electrical heaters ( $600 \mathrm{~W}$ each) located in the liner. Three thermocouples measure the walls temperature in the liner, in the piston and in the bowl, respectively. Fully controlled initial and boundary conditions are guaranteed thanks to the turbulence generated during the filling, which ensures a homogeneous environment in the combustion chamber, as demonstrated by some previous CFD calculations [37].

A Kistler 6045A uncooled piezoelectric pressure sensor with a sensitivity of $-45 p C / b a r$, which is coupled to a Kistler 5018 charge amplifier, is located in the cylinder head. The initial pressure of the test sample, as well as the driving gas pressure, are measured by three Wika piezoresistive pressure sensors with a resolution of 0.01 bar. The injection system, which is a standard common rail system that includes a BOSCH solenoid-commanded injector with a 7-hole nozzle and that is controlled by a EFS IPod power driving module, has been characterized as explained in [38].

The acquisition system is a Yokogawa DL850V composed by one $10 \mathrm{M} \mathrm{Hz}$ - 
12 bits module and five more $1 M H z$-16 bits modules with two channels each. The acquisition frequency is fixed to $10 \mathrm{MHz}$ in order to record the pulses of the incremental position sensor, while $1 \mathrm{MHz}$ is selected to record the in-cylinder pressure and the injection pressure.

The synthetic air, which is produced in an external tank that can be heated up to $520 \mathrm{~K}$ by means of three electrical heaters of $1200 \mathrm{~W}$ each, can be composed by $\mathrm{N}_{2}, \mathrm{CO}_{2}, \mathrm{O}_{2}$ (by means of a filling based on partial pressures) and $\mathrm{H}_{2} \mathrm{O}$ (by means of a syringe pump). Vacuum is created to ensure the no contamination of the mixture in the tank, nor in the RCEM charge. Finally, the synthetic air is analyzed by gas chromatography in a Rapid Refinery Gas Analyser from Bruker (450-GC) in order to know its exact composition.

\section{Methodological approach}

\subsection{Parametric study performed}

The experimental settings are the following:

- Fuel: n-dodecane.

- Oxygen molar fraction $\left(\mathrm{X}_{\mathrm{O}_{2}}\right): 0.21$ and 0.15 .

- Equivalence ratio $(F r): 0.8,0.9$ and 1 .

272 In this study, the target standard ECN conditions are imposed at TDC, which cover a wide range of temperatures, oxygen molar fractions, and equivalence ratios, while the pressure value is selected to keep a constant density at TDC equal to $22.8 \mathrm{~kg} / \mathrm{m}^{3}$. Thus, the compression ratio and stroke are 
defined by the maximum heating temperature of the machine $\left(T_{i}\right)$, which is reached at start of compression, and the maximum temperature required at TDC, fixing all the other initial conditions. Specifically, a compression stroke equal to $120 \mathrm{~mm}$ and a compression ratio $(C R)$ equal to 16.77 have been selected. In fact, the performed parametric study can be seen in Table 2, where the desired conditions at TDC are specified, as well as the required initial values. Moreover, the minimum compression stroke available has been selected in order to more easily achieve a homogeneous environment. The maximum equivalence ratio is limited by the working oxygen molar fraction in order to avoid extremely violent combustions. Thus, a parametric variation of equivalence ratios have been performed below the stoichiometric value. Richer equivalence ratios have not been tested in order to avoid extremely violent combustions.

\begin{tabular}{|c|c|c|c|}
\hline $\mathbf{T}_{i}[K]$ & $\mathbf{T}_{T D C}[K]$ & $\mathbf{P}_{i}[$ bar $]$ & $\mathbf{P}_{\text {TDC }}[$ bar $]$ \\
\hline 394 & 850 & 1.49 & 53.90 \\
\hline 417 & 900 & 1.68 & 60.69 \\
\hline 440 & 950 & 1.77 & 64.10 \\
\hline 463 & 1000 & 1.86 & 67.47 \\
\hline
\end{tabular}

Table 2: Parametric study performed for two oxygen molar fractions (0.21 and 0.15$)$ and three equivalence ratios $(0.8,0.9$ and 1$)$.

The ignition of the fuel always occurs during the compression stroke due to the long compression times $(\approx 17 \mathrm{~ms})$, which means that the thermodynamic conditions of ignition are not the ones imposed at TDC. However, since the compression ratio is constant for all the operating points, the ef- 
fects of the thermodynamic conditions on the ignition delay can be properly studied by varying the initial condition (as it has been done in this work).

\subsection{Experimental methodology}

In this work, the oxygen dilution is performed by creating a synthetic mixture with $\mathrm{N}_{2}$ and $\mathrm{O}_{2}$, which is the standard composition of the synthetic EGR in ECN studies. Vacuum is created in the combustion chamber before the filling and the fuel is injected into the combustion chamber at the start of the intake process, avoiding problems of fuel stratification. Moreover, starting from vacuum ensures the vaporization of the fuel in spite of working with initial temperatures below the boiling point at ambient pressure. The long duration of the filling process (aproximately $40 \mathrm{~s}$ ) ensures homogeneous initial conditions in the chamber.

The pressure and temperature profiles under motoring conditions can be seen in Fig. 1, where an inert mixture composed by $\mathrm{CO}_{2}$ and $\mathrm{N}_{2}$ has been tested in order to replicate the same polytropic index as the reactive mixture. Besides, the modeled profiles from CHEMKIN are also plotted and they will be discussed in Section 3.3. The behavior reproduced in the figure corresponds to a mixture with an oxygen content of $21 \%$ and an equivalence ratio of 0.9 . However, the changes in the polytropic index between the different operating conditions cause variations in the thermodynamic conditions at TDC within the confidence interval defined by the repeatability of the machine $\left(\Delta T_{T D C}<8 \mathrm{~K}, \Delta P_{T D C}<1.5 \mathrm{bar}\right)$. Thus, the results shown in Fig. 1 can been extended to any other mixture. Besides, it can be seen that the required conditions are guaranteed.

Fig. 1 also shows that different initial conditions lead to different compres- 

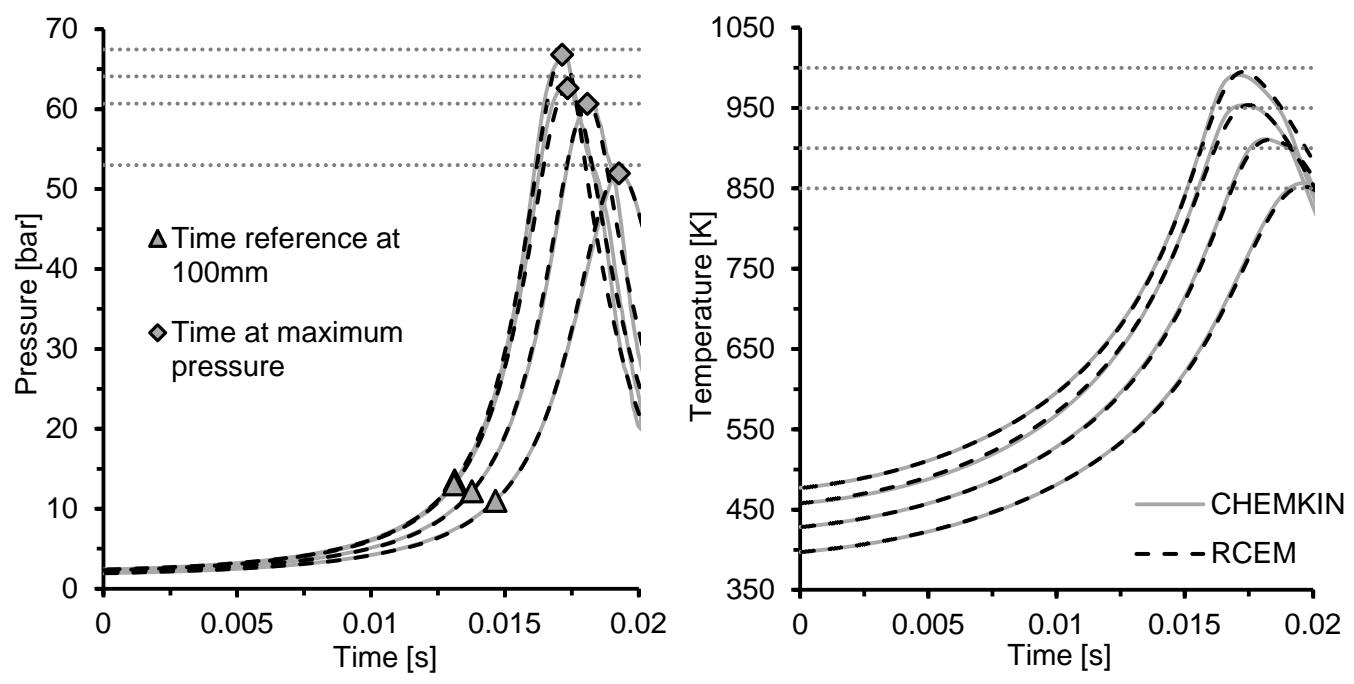

Figure 1: In-cylinder thermodynamic conditions under motoring conditions for an oxygen content of $21 \%$ and an equivalence ratio of 0.9. Solid line.- Homogeneous closed 0-D reactor from CHEMKIN. Dashed line.- Experimental measurement. Left.- Pressure. Right.Temperature. 
sion times. The piston stops when the pressure in the combustion chamber is high enough to compensate the pushing force and the inertia, defining TDC. Thereby, TDC is highly dependent on the operation conditions of the RCEM, which is completely different for engines, since in the RCEM there is not any mechanism as the rod-crank mechanism that fixes the maximum position of the piston. Thus, a position-based definition of the time reference for the ignition delay is needed to be able to compare ignition delays under different working conditions. The compression time can be normalized by setting $100 \mathrm{~mm}$ as the reference position to start measuring the ignition delay. In fact, the reference times based on $100 \mathrm{~mm}$ are plotted in Fig. 1 Left, showing a normalized base time for all the operating points. Furthermore, the autoignition of the mixture is considered to be produced when the first signs of combustion are visible, which can be easily seen in the HRR profile. More specifically, ignition is defined as the crossing through zero of a secant line of the HRR as described in Fig. 2. As it can be seen, both cool flames and the high-temperature stage of the process can be identified when a two-stage ignition pattern occurs. The points at $75 \%$ and $25 \%$ of the maximum HRR referred to each ignition stage are selected for the calculation of the secant line and the subsequent ignition time. Thus, the ignition delay $\left(t_{i, 1-i n i}\right.$ or $t_{i, 2-i n i}$ for cool flames and high-temperature, respectively) in the experimental facility is defined as the time between the start of the rapid compression process and the calculated (from the start of the HRR) ignition time.

Moreover, the Livengood \& Wu integral method [39] has been applied in order to evaluate the chemical activity that occurs previously to the time reference for the measurement of the ignition delay. Calculations show that 


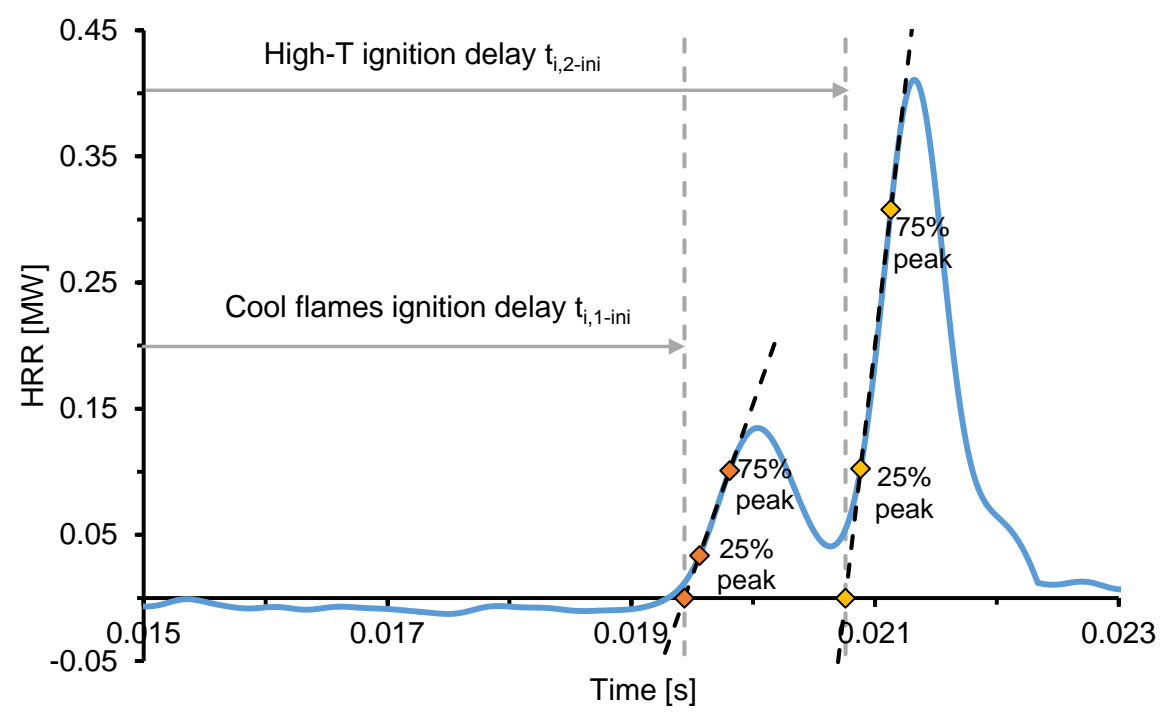

Figure 2: Ignition delay definition. The autoignition of the mixture is considered to be produced when the crossing through zero of a secant line of the HRR occurs.

the accumulated value of the integral method, the area of which represents the accumulation of chain carriers during the ignition delay, from bottom dead center (BDC) to the instant in which the piston position reaches $100 \mathrm{~mm}$ (time reference for the definition of the ignition delay) is lower than a $5 \%$ of the whole area.

The number of repetitions of each operating point has been selected so that the half-amplitude of the confidence interval with a level of confidence of $95 \%$ is smaller than $1 \%$ of the mean ignition delay value, which ensures representative measurements.

Finally, the temperature profile is calculated by applying the equation of state, including models for deformations and leakages [40, 41]. Heat losses, which are used in the simulations to reproduce the RCEM conditions, are 


\begin{tabular}{|l|c|c|c|c|}
\hline \multicolumn{1}{|c|}{ Mechanism } & Species & Reactions & Reduced from & Ref. \\
\hline LLNL detailed & 2885 & 11754 & - & {$[13]$} \\
\hline Cai & 1692 & 5804 & - & {$[26]$} \\
\hline LLNL reduced & 163 & 887 & LLNL detailed $[13]$ & {$[14]$} \\
\hline Narayanaswamy & 225 & 1509 & LLNL detailed $[13]$ & {$[16]$} \\
\hline Luo & 105 & 420 & LLNL detailed $[13]$ & {$[15]$} \\
\hline Wang & 100 & 432 & You $[23]$ & {$[19]$} \\
\hline Yao & 54 & 269 & archived LLNL detailed $[20]$ & {$[22]$} \\
\hline
\end{tabular}

Table 3: Chemical kinetic mechanisms evaluated.

characterized by a model based on the Woschni correlation [42]. The HRR is obtained from the energy equation by applying all the previous models, i.e., taking into account deformations, leaks and heat losses.

\subsection{CHEMKIN and chemical kinetic mechanisms}

CHEMKIN-PRO is the software used to replicate the RCEM behavior and to obtain the different simulated ignition delays. The five reduced chemical kinetic mechanisms described in Section 1, as well as the two detailed chemical kinetic mechanisms (one proposed by LLNL [13] and the other by Cai et al. [26]), have been evaluated. A summary of all the mechanisms computed can be seen in Table 3 .

Two different ignition delays are defined in the simulations:

- $t_{i, 1}$ is the ignition delay under transient thermodynamic conditions referred to the crossing through zero of the secant line that passes through 
the $75 \%$ and the $25 \%$ of the maximum HRR caused by cool flames. This ignition delay is also experimentally obtained.

- $t_{i, 2}$ is the ignition delay under transient thermodynamic conditions referred to the crossing through zero of the secant line that passes through the $75 \%$ and the $25 \%$ of the maximum HRR caused by the high-temperature stage of the combustion process. This ignition delay is also experimentally obtained.

The model used to obtain the ignition delays under transient conditions $\left(t_{i, 1}\right.$ and $\left.t_{i, 2}\right)$ is a reciprocating internal combustion engine operating with homogeneous charge (IC-engine, closed 0-D reactors from CHEMKIN). The volume profile as well as the heat losses profile are imposed in order to reproduce the RCEM conditions. The piston starts at BDC and a complete cycle of the RCEM is simulated. From Fig. 1, the 0-D model can be seen to replicate with high accuracy the thermodynamic conditions reached in the facility. Moreover, while the experimental measurements have been performed with a synthetic mixture composed by $\mathrm{CO}_{2}$ and $\mathrm{N}_{2}$ in order to reproduce the polytropic index of the air-fuel mixture, the simulations have been performed assuming the real composition of the mixture (n-dodecane $+\mathrm{O}_{2}+\mathrm{N}_{2}$ ) but avoiding the chemistry. Thus, the thermodynamic accuracy of the model is guaranteed for real air-fuel mixtures. It should be noted that the piston kinematics is different during the expansion and the compression stroke. Thus, the heat losses will also be different and an alternative fitting should be performed in the corresponding model, since the Woschni correlation in which it is based depends on the velocities involved in the process. Since the ignition of the n-dodecane always occurs before TDC and the aim of this study is to 
evaluate chemical mechanisms according to ignition delay, the models have been fit only for the compression stroke, so that a worse matching between experiments and simulations can be seen in Fig. 1 during the expansion.

Finally, the autoignition is considered to be produced following the same criterion than the one used in the experiments and, therefore, it allows comparing the simulated results directly with the experimental ones.

\section{Results, validation and discussion}

The experimental trends of ignition delay are discussed in this section. Besides, ignition delays obtained solving the different chemical kinetic mechanisms for n-dodecane are compared to the experimental results as a method to validate the mechanism in the desired range. Two different events are studied from a point of view of the auto-ignition process: cool flames and the high exothermic stage of the ignition process. Finally, the differences between mechanisms are identified and analyzed.

\subsection{Experimental tends of the ignition delay}

As said before, for the investigated conditions, fuel autoignition always occurs during the compression stroke, meaning that the thermodynamic conditions of ignition are not the ones imposed at TDC. However, this fact does not invalidate the results, since the compression ratio is constant for all the operating points. Thus, the effect of the temperature on the ignition delay can be properly studied by varying the initial condition (as it has been done in this work). Moreover, the analysis of the different mechanisms can be carried out, since the in-cylinder pressure and temperature evolution is properly characterized. Furthermore, the normalized compression time, defined as the 
time between a piston position equal to $100 \mathrm{~mm}$ and the TDC time, is $\approx$ $4.3 \mathrm{~ms}$.

Finally, it should be taken into account that, under transient thermodynamic conditions as the ones present in the RCEM, the thermodynamic conditions of ignition are not good parameters to study the ignition delay behavior, since the ignition delay depends on the temperature and pressure evolution, i.e., on the in-cylinder temperature and pressure conditions reached during the compression stroke before the ignition point. Thus, a characteristic temperature and pressure of the process should be used if the effects of the thermodynamic conditions on the ignition delay want to be studied. Since the compression ratio remains constant for all the experiments, either the initial temperature and pressure or the temperature and pressure values at TDC are good characteristic parameters of the in-cylinder conditions variation. However, the ignition conditions can be interesting in order to compare the ignition delay from the RCEM with the ignition delay under constant conditions obtained from shock-tube experiments. Thus, the autoignition conditions have been summarized in Appendix A.

Fig. 3 shows the ignition delay trends for the ignition delay referred to the high-temperature stage, $t_{i, 2}$, versus temperature at TDC for different equivalence ratios and oxygen molar fractions. The confidence intervals with a level of confidence of $95 \%$ for the mean ignition delay values are plotted as error bars in the figure. Besides, the chromatographic analysis of the test samples shows that the relative deviation in oxygen molar fraction between the real and desired mixtures is always lower than $1.7 \%$. The simulated ignition delays obtained by solving the LLNL detailed chemical kinetic mechanism in an 

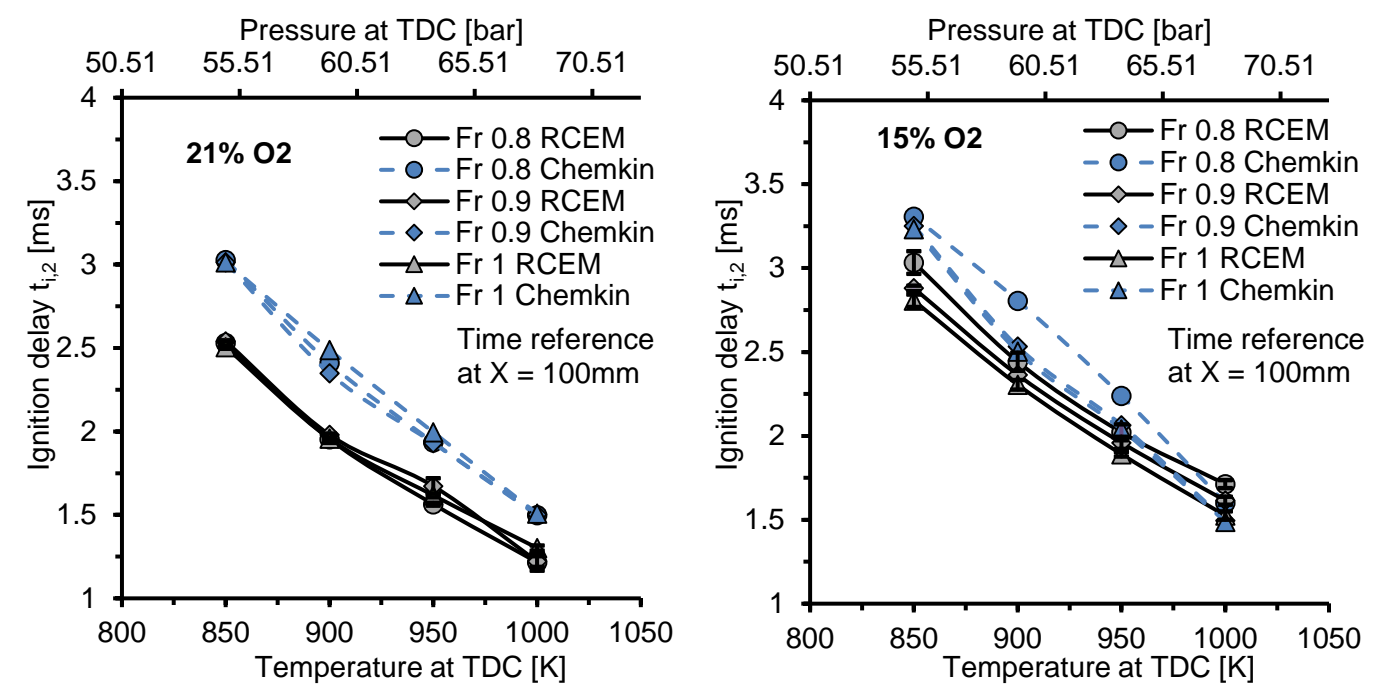

Figure 3: Ignition delay referred to the high-temperature stage, $t_{i, 2}$, versus initial temperature for different equivalence ratios and oxygen molar fractions. The normalized compression time is $\approx 4.3 \mathrm{~ms}$. Left.- $21 \% \mathrm{O}_{2}$. Right.- $15 \% \mathrm{O}_{2}$.

internal combustion engine model that replicates the RCEM conditions have also been plotted in the figure. It can be seen that both experimental and modeling trends are consistent, which is an indicator of the measurements reliability.

It can be seen that the ignition delay decreases if the temperature is increased in the whole range. The Negative Temperature Coefficient (NTC) zone, in which the ignition delay increases with temperature because of the competence between the low temperature chain branching and the formation of long and stable olefines by the alkyl radicals, is not present in these experimental measurements. Fig. 4 shows the autoignition characteristics under constant conditions for different temperature and pressure. It can be seen that the NTC zone is smoother and it is moved towards higher temperatures 


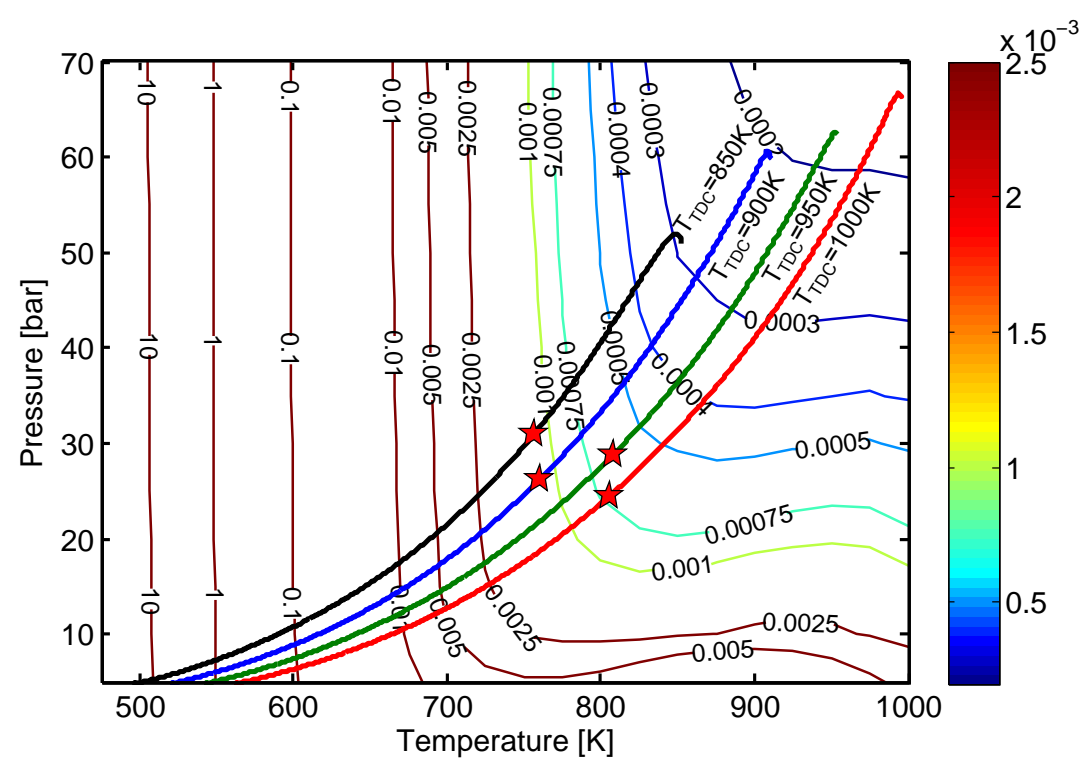

Figure 4: Autoignition map for $F r=1$ and $X_{O_{2}}=0.21$. The in-cylinder conditions for a temperature at TDC equal to $1000 \mathrm{~K}, 950 \mathrm{~K}, 900 \mathrm{~K}$ and $850 \mathrm{~K}$ are plotted in red, green, blue and black, respectively. The ignition point is also represented as a red star.

if the pressure is increased. Thus, since the higher the initial temperature the higher the initial pressure in order to keep a constant density at TDC, pressure effects on the NTC zone compensate the variation of temperature, and the ignition is characterized by the absence of such phenomenon for the thermodynamic conditions tested in this work. In fact, the in-cylinder conditions are plotted also in Fig. 4, where the ignition point is represented as a red star, and it can be seen that the thermodynamic conditions reached in the combustion chamber are out of the NTC zone during the ignition delay. Moreover, Fig. 3 shows that for an oxygen content of $15 \%$ the ignition delay decreases when the equivalence ratio increases. However, the ignition delay seems to be independent on the equivalence ratio for an oxygen molar 
fraction of $21 \%$. On the one hand, ignition is promoted by the accumulation of chain carriers under low temperature conditions. Thus, the higher the equivalence ratio, the higher the accumulation rate of chain carriers and the shorter the ignition delay. On the other hand, ignition delay can be generally scaled with the equivalence ratio and the oxygen content by $\tau \sim \mathrm{Fr}^{-a} \mathrm{X}_{\mathrm{O}_{2}}^{-b}$, where $a$ and $b$ are positive numbers [43]. Thus, the higher the equivalence ratio, the lower the ignition delay variation caused by this parameter, being the ignition delay almost constant if the equivalence ratio is varied around the stoichiometric value. Furthermore, if the oxygen content is decreased, the differences in ignition delay caused by a variation of equivalence ratio become more relevant, which means that the ignition delay is more sensitive to changes in the equivalence ratio if the reactivity of the mixture is reduced, since the low-temperature chain branching reactions, which depend on the amount of fuel, are more dominant.

Fig. 3 also shows the dependence of the ignition delay on the oxygen content. The ignition delay increases when the oxygen molar fraction of the mixture is reduced, since lower amount of oxidizer implies lower reactivity.

In terms of cool flames, Fig. 5 shows that this phenomenon is mainly dependent on temperature. Once again, the confidence intervals with a level of confidence of $95 \%$ for the mean ignition delay values are plotted as error bars in the figure. The simulated ignition delays obtained by solving the LLNL detailed chemical kinetic mechanism in an internal combustion engine model that replicates the RCEM conditions have been also plotted in the figure. It can be seen that both experimental and modeling trends are consistent, which is an indicator of the measurements reliability. The ignition delay 
referred to cool flames is always shorter if the temperature is increased. Obviously, the ignition delay referred to cool flames does not increase during the NTC zone, since it occurs before the loss of reactivity that causes a two-stage ignition pattern. Moreover, ignition delay sensitivity to equivalence ratio of the mixture is really low despite ignition delay referred to cool flames seems to decrease if equivalence ratio increases. Finally, ignition delay referred to cool flames is also shorter if the percent of oxygen is increased. However, the effect of the amount of oxygen on ignition delay for cool flames is lower than for the high-temperature stage. Cool flames occur due to the slightly exothermic reactions of the initial low-temperature branching mechanism. The H-abstraction of the fuel, $R H$, by its combination with the molecular oxygen, $\mathrm{RH}+\mathrm{O}_{2}=\mathrm{R}+\mathrm{HO}_{2}$, is endothermic [44]. Thus, this reaction becomes less relevant when enough active radicals are generated, so that the oxygen content becomes less relevant for cool flames.

\subsection{Validation of the different chemical kinetic mechanisms}

The seven chemical kinetic mechanisms summarized in Table 3 have been tested by replicating the RCEM conditions in a 0-D model. Each of them will be identified with the name that is given in Table 3 .

Fig. 6 shows the simulated and experimental pressure traces, including also an adiabatic simulation, for the most and the least reactive cases by solving the LLNL detailed chemical kinetic mechanism. As it can be seen, higher pressures are reached in the simulations after the ignition because of the wall effects existing in the experiments that cannot be suitably reproduced in a 0-D model. However, 0-D models are really useful for autoignition investigations of homogeneous mixtures, since detailed chemical kinetic mechanisms 

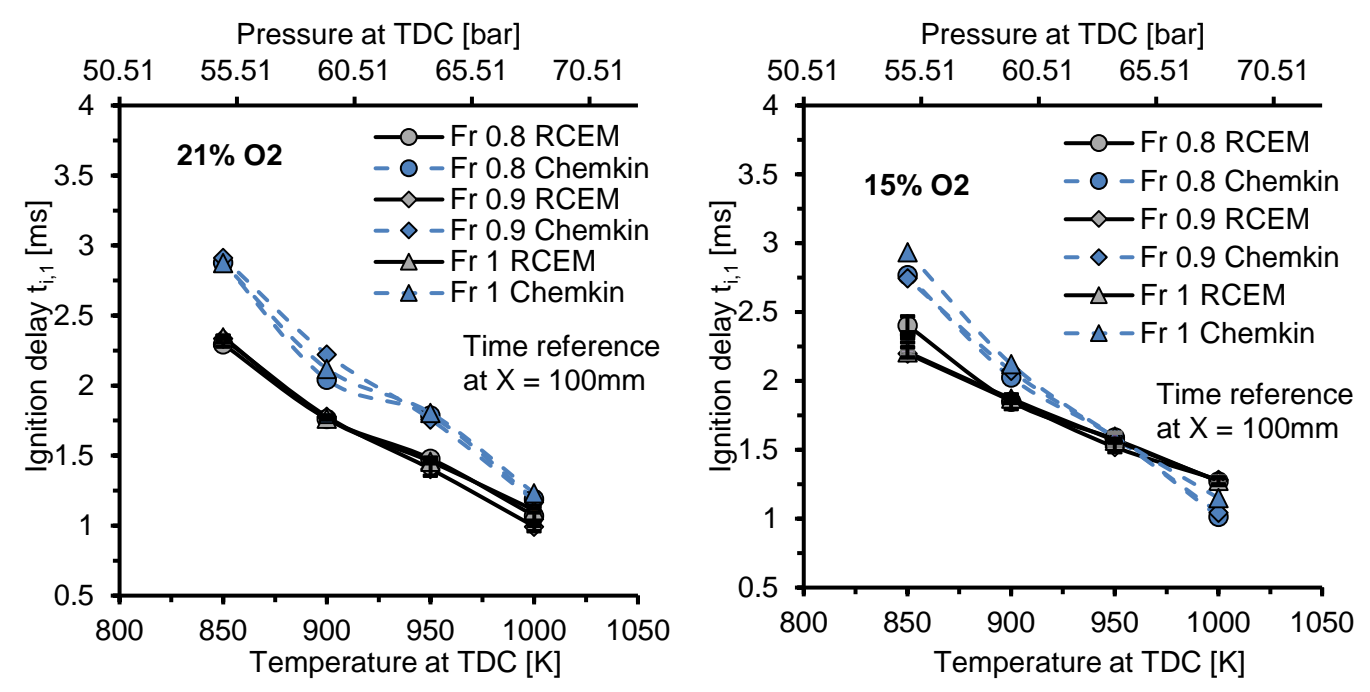

Figure 5: Ignition delay referred to cool flames, $t_{i, 1}$, versus initial temperature for different equivalence ratios and oxygen molar fractions. The normalized compression time is $\approx$ $4.3 \mathrm{~ms}$. Left.- $21 \% \mathrm{O}_{2}$. Right.- $15 \% \mathrm{O}_{2}$. 
can be easily evaluated, whereas their implementation in CFD simulations can be impossible. Besides, if the thermodynamic conditions during the compression stroke are properly characterized (perfect matching between simulations and experiments during the ignition delay, as shown in the figure), the predicted ignition delay is directly comparable to the experimental one. It should be noted that the combustion efficiency cannot be properly modeled, while wall effects before the ignition are not so relevant. Finally, the equivalent polytropic index before the ignition, $k$, have been obtained in each case and the value can be seen in the figure, which allows a qualitative measurement of the relevance of heat losses by comparing this value to the mean adiabatic coefficient, $\gamma$, of the mixture during the compression stroke (also given in the figure).

Fig. 7 and Fig. 8 show the simulated ignition delays versus the experimental ones referred to cool flames (left) and to the high-temperature stage (right). The line $y=x$, which represents a perfect match between values, has been also plotted in the figures. Finally, the Pearson's coefficient of correlation, $R^{2}$, has been calculated for each chemical kinetic mechanism and its value has been added to the figures.

Figs. 7 and 8 show that the longer the ignition delay, the more overpredicted the instant at which ignition occur is, especially for cool flames. It should be taken into account that the experimental results are affected by wall effects that are not included in the simulations. Thus, more sudden heat release rates are presented in the numerical results, which leads to a certain trend to under-predict the ignition time. However, this fact does not explain the behavior at long ignition delays. The over-estimation of the ignition delay 

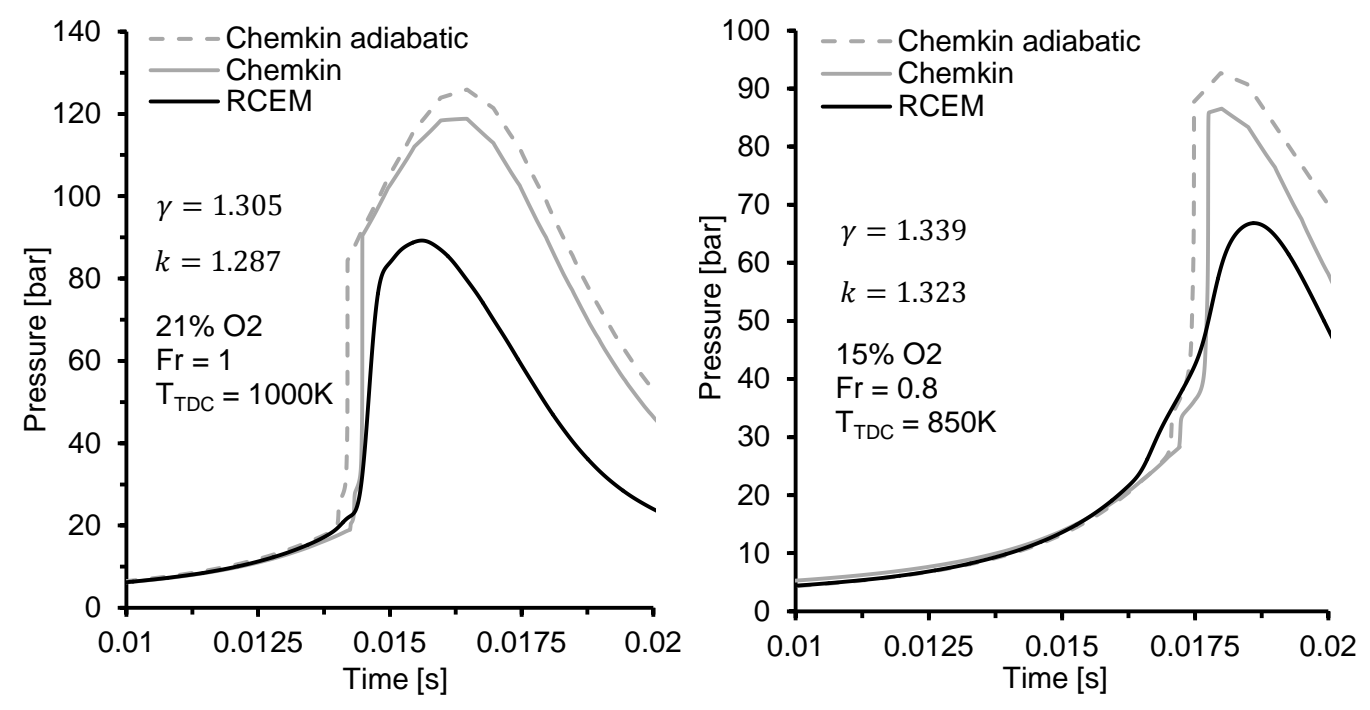

Figure 6: Simulated and experimental pressure traces for the most and the least reactive cases. Left.- $\mathrm{T}_{T D C}=1000 \mathrm{~K}, 21 \% \mathrm{O}_{2}, \mathrm{Fr}=1$. Right.- $\mathrm{T}_{T D C}=850 \mathrm{~K}, 15 \% \mathrm{O}_{2}, \mathrm{Fr}=$ 0.8 . 

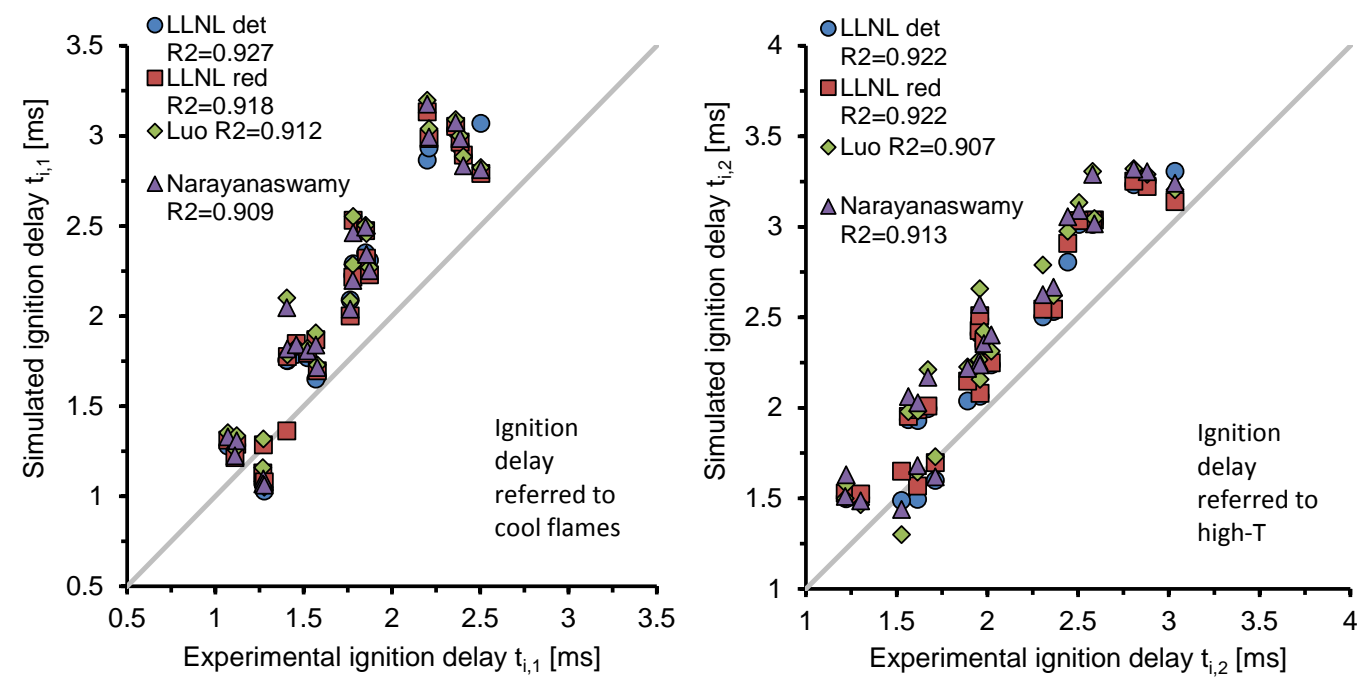

Figure 7: Ignition delays from chemical simulations with CHEMKIN using a closed 0-D IC-engine reactor versus the experimental ignition delays. The seven chemical kinetic mechanisms summarized in Table 3 have been tested, while four of them (LLNL detailed, LLNL reduced, Luo and Narayanaswamy) are plotted in this figure. Left.- Ignition time referred to cool flames, $t_{i, 1}$. Right.- Ignition time referred to the high-temperature stage, $t_{i, 2}$.

is a phenomenon already seen by Hawkes [5] when the chemical mechanisms of n-dodecane used in this work are solved under ECN conditions. Probably, the chemical description of cool flames is not completely accurate, as it has been checked by Cai et al. [26]. In fact, the improvements of Bugler et al. [27] and Cai et al. [26] lead to a more accurate estimation of the ignition delay referred to cool flames in the Cai's mechanism.

The relative deviation in ignition delay $(\epsilon)$, which has been calculated in order to more easily compare experimental and simulation results, is defined as follows: 

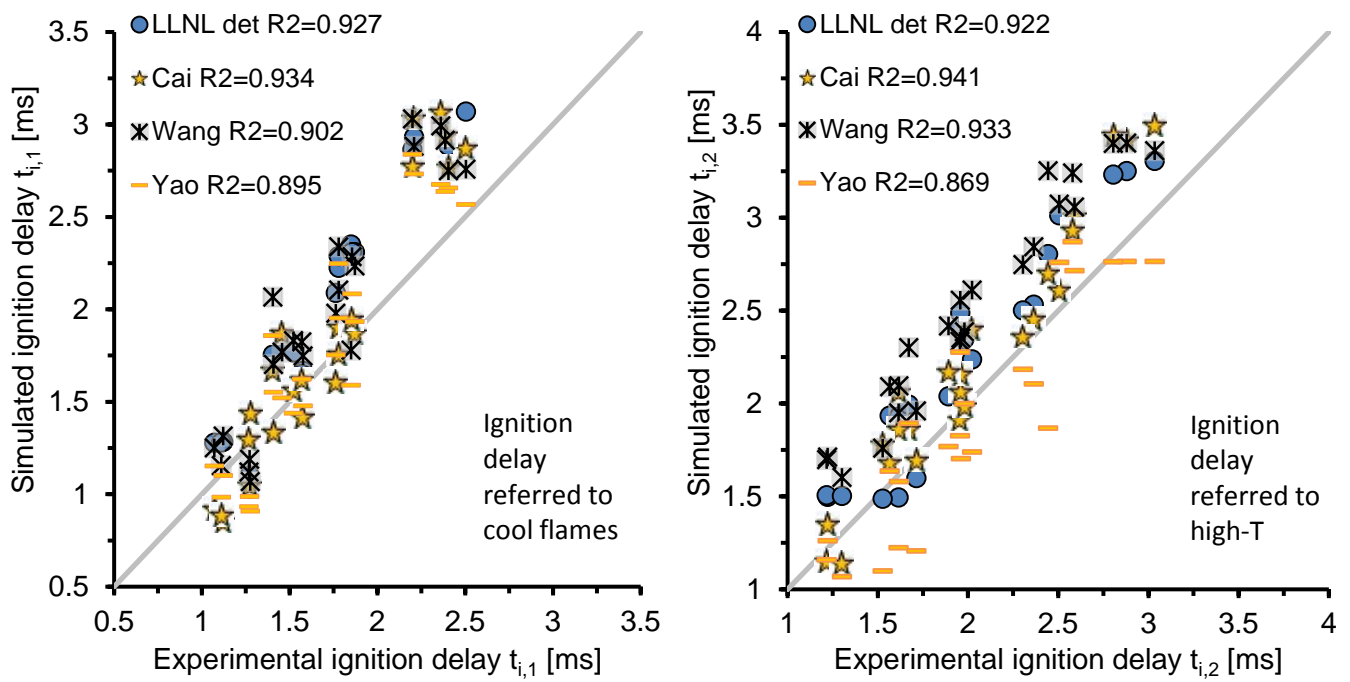

Figure 8: Ignition delays from chemical simulations with CHEMKIN using a closed 0-D IC-engine reactor versus the experimental ignition delays. The seven chemical kinetic mechanisms summarized in Table 3 have been tested, while four of them (LLNL detailed, Cai, Wang and Yao) are plotted in this figure. Left.- Ignition time referred to cool flames, $t_{i, 1}$. Right.- Ignition time referred to the high-temperature stage, $t_{i, 2}$. 


$$
\epsilon=\frac{t_{i, x}-t_{i, R C E M}}{t_{i, R C E M}} 100
$$

where $t_{i}$ represents the ignition delay, which can be referred to cool flames, $t_{i, 1}$, or to the high-temperature stage, $t_{i, 2}$. The subscript $x$ represents data obtained from a chemical simulation with CHEMKIN using the closed 0-D IC-engine reactor and one of the tested mechanisms. Finally, the subscript $R C E M$ represents data obtained experimentally from the RCEM.

The mean absolute deviations, $|\bar{\epsilon}|=\sum|\epsilon| / N$, have been calculated, as well as their confidence intervals with a confidence level of $95 \%$, and their values for each chemical kinetic mechanism have been summarized in Table 4. The values of $|\bar{\epsilon}|$ are very similar to each other, meaning that the reduced chemical kinetic mechanisms have, in general, a similar accuracy to the detailed ones. It can be seen that the relative deviations related to cool flames are usually higher than the corresponding values referred to the high-temperature stage. However, the improvements in the cool flames description [26] lead to closer correspondences for Cai's mechanism. As said before, this fact is probably caused by a not completely accurate chemical description of cool flames, since the existence of wall effects in the experiments would lead to the opposite trend in the cool flames deviations (wall effects caused an under-estimation of the ignition delay).

Finally, the ignition delay deviation in CAD has been also calculated in order to more easily evaluate the accuracy of the different mechanisms with respect to engine simulations. Such deviation is defined as follows:

$$
\epsilon=180 \frac{t_{i, x}-t_{i, R C E M}}{t_{\text {compression }}}
$$




\begin{tabular}{|c|c|c|c|c|c|}
\cline { 2 - 6 } \multicolumn{1}{c|}{} & \multicolumn{2}{c|}{ Cool flames } & \multicolumn{2}{c|}{ High-T stage } & \multirow{2}{*}{} \\
\hline Mechanism & $|\bar{\epsilon}|[\%]$ & CI 95\%[\%] & $|\bar{\epsilon}|[\%]$ & CI 95\% [\%] & Species \\
\hline LLNL detailed & 19.207 & {$[14.842-23.571]$} & 16.682 & {$[11.324-22.039]$} & 2885 \\
\hline Cai & 14.742 & {$[10.772-18.712]$} & 11.343 & {$[8.371-14.316]$} & 1692 \\
\hline LLNL reduced & 20.289 & {$[15.836-24.743]$} & 17.607 & {$[12.198-23.016]$} & 163 \\
\hline Narayanaswamy & 20.658 & {$[15.891-25.425]$} & 20.304 & {$[14.947-25.662]$} & 225 \\
\hline Luo & 21.394 & {$[16.322-26.466]$} & 19.986 & {$[14.483-25.489]$} & 105 \\
\hline Wang & 17.027 & {$[13.036-21.017]$} & 24.580 & {$[18.901-30.259]$} & 100 \\
\hline Yao & 13.126 & {$[10.035-16.218]$} & 13.738 & {$[9.723-17.753]$} & 54 \\
\hline
\end{tabular}

Table 4: Confidence intervals for the mean absolute deviation referred to both, cool flames and high-temperature stage, $|\bar{\epsilon}|$, with a confidence level of $95 \%$ for all the different chemical kinetic mechanisms.

where the subscripts are analogous than the ones for Eq. 1. The mean absolute deviation, $|\bar{\epsilon}|_{C A D}$, has been calculated for each mechanism, as well as their confidence intervals with a confidence level of $95 \%$, the values of which can be seen in Table 5. It should be noted that despite the fact that deviations in Table 4 seems to be high, the accuracy of the different mechanisms is quite good according to the CAD values. Assuming that the ignition deviation is independent on the different physical models and, therefore, the ignition accuracy of a CFD engine simulation is controlled by the chemical kinetic mechanism, the accuracy of the tested mechanisms seems to good enough to estimate the heat release rate and the fuel consumption, but not to simulate the maximum pressure, noise or pollutant emissions. Furthermore, CAD deviations for the high-temperature ignition delay from Wang's mechanism can be too high even to obtain a proper simulated HRR. 


\begin{tabular}{|c|c|c|c|c|c|}
\cline { 2 - 5 } \multicolumn{1}{c|}{} & \multicolumn{2}{c|}{ Cool flames } & \multicolumn{2}{c|}{ High-T stage } & \multicolumn{1}{c}{} \\
\hline Mechanism & $|\bar{\epsilon}|_{C A D}[C A D]$ & CI 95\% $[C A D]$ & $\left.\bar{\epsilon}\right|_{C A D}[C A D]$ & CI 95\% [CAD] & Species \\
\hline LLNL detailed & 3.367 & {$[2.515-4.220]$} & 3.197 & {$[2.166-4.228]$} & 2885 \\
\hline Cai & 2.580 & {$[1.718-3.382]$} & 2.339 & {$[1.670-3.008]$} & 1692 \\
\hline LLNL reduced & 3.557 & {$[2.693-4.422]$} & 3.371 & {$[2.338-4.404]$} & 163 \\
\hline Narayanaswamy & 3.634 & {$[2.719-4.546]$} & 3.879 & {$[2.907-4.851]$} & 225 \\
\hline Luo & 3.759 & {$[2.800-4.717]$} & 3.858 & {$[2.826-4.890]$} & 105 \\
\hline Wang & 2.972 & {$[2.239-3.705]$} & 4.649 & {$[3.759-5.540]$} & 100 \\
\hline Yao & 2.280 & {$[1.719-2.841]$} & 2.720 & {$[1.941-3.499]$} & 54 \\
\hline
\end{tabular}

Table 5: Confidence intervals for the mean absolute deviation in CAD referred to both, cool flames and high-temperature stage, $|\bar{\epsilon}|_{C A D}$, with a confidence level of $95 \%$ for all the different chemical kinetic mechanisms.

\subsection{Chemical kinetic analysis among mechanisms}

The differences among mechanisms are explained in this section from a chemical kinetics point of view. To do so, a comparison is shown in Fig. 9, in which the relative deviations of all the skeletal mechanisms and of the Cai's detailed mechanism (as defined in Eq. 1) are compared to the relative deviation of the LLNL detailed mechanism, for all cases and both ignition events.

In Fig. 9 to the left, it can be seen that Cai's, Yao's and Wang's mechanisms (specially the two first) tend to under-predict the ignition delay referred to cool flames compared to the LLNL detailed one, while the other reduced mechanisms lead to similar deviations. This is an expected result, since whereas LLNL reduced, Narayanaswamy's and Luo's mechanisms have been reduced from the LLNL detailed mechanism (and, therefore, similar results are obtained by using any of these four mechanisms), Yao's and 

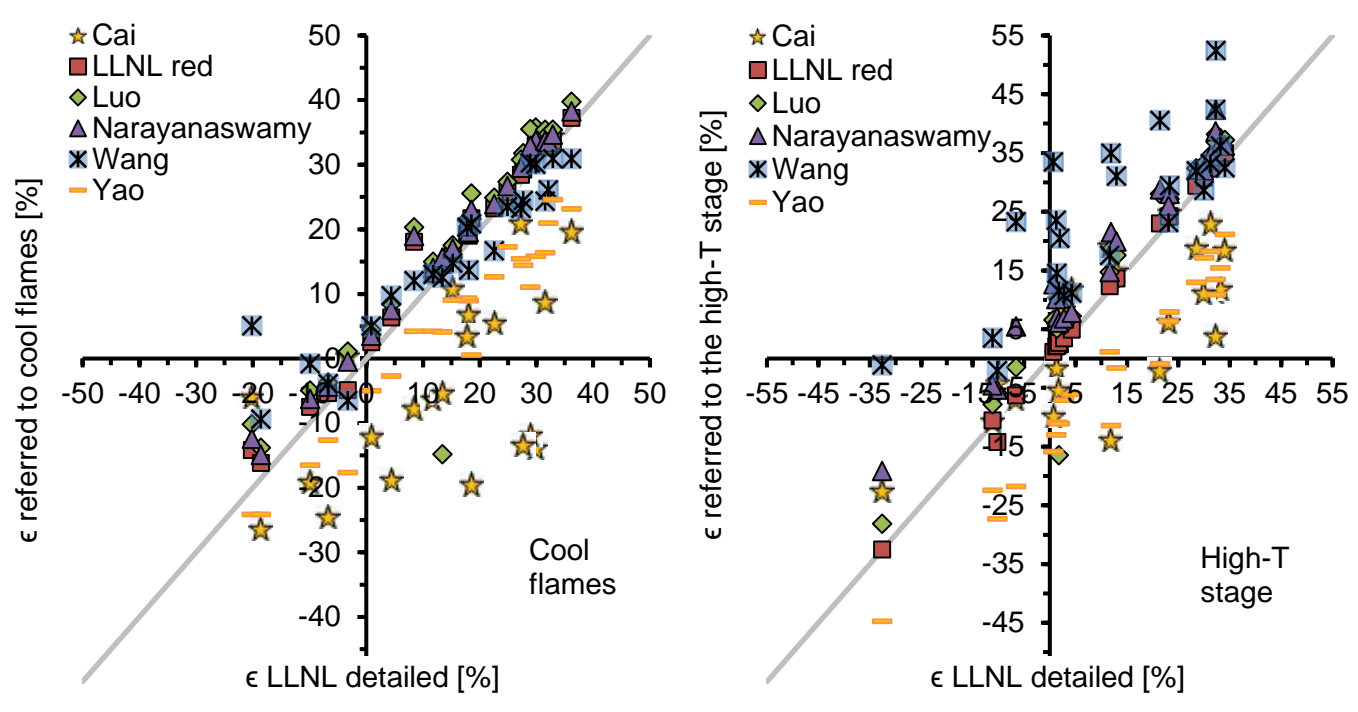

Figure 9: Relative deviations in ignition delay for the reduced mechanisms versus the corresponding relative deviation for the LLNL detailed mechanism. Left.- Deviations referred to cool flames. Right.- Deviations referred to the high-temperature stage.

Wang's mechanisms have been obtained from other sources. Besides, Cai's mechanism includes not only modified specific reaction rates for the lowtemperature chain branching mechanism, but also additional reaction pathways. The Cai's chemical kinetics improvements are explained in detail in $[26,27]$. These modifications respect to the LLNL detailed mechanism lead to shorter ignition delays referred to cool flames, which results in a narrow range of relative deviations (i.e., closer correspondence).

The LLNL detailed mechanism is assumed as the reference to compare the differences between mechanisms. Thus, if a certain specific reaction rate is higher in other mechanism, it is described as an enhanced reaction, independently on the source of such increment. Furthermore, despite the fact that 
$\mathrm{HO}_{2}$ has demonstrated to be a good tracer of the cool flames phenomenon [36], so that the chemical kinetics of such species is traced to explain the differences between mechanisms according to cool flames. The main accumulation reactions of $\mathrm{HO}_{2}$ have been assessed by integrating the different rates of production of such species during the simulation up to the first $\mathrm{HO}_{2}$ peak, which coincides with cool flames. Thus, the most relevant reaction according to $\mathrm{HO}_{2}$ generation can be identified. On the one hand, the main accumulation reaction of $\mathrm{HO}_{2}$ in the detailed mechanism is:

$$
\mathrm{H}+\mathrm{O}_{2}+\mathrm{M} \rightarrow \mathrm{HO}_{2}+\mathrm{M}
$$

which is a third body reaction highly dependent on pressure. On the other hand, the main accumulation reaction of $\mathrm{HO}_{2}$ in both Yao's and Wang's mechanisms is:

$$
\mathrm{HCO}+\mathrm{O}_{2} \rightarrow \mathrm{CO}+\mathrm{HO}_{2}
$$

611

It has been checked that R2 is a dominant chemical path for the generation of $\mathrm{HO}_{2}$ in Yao's and Wang's due to the following reaction (enhanced with respect to the LLNL detailed mechanism):

$$
\mathrm{CH}_{2} \mathrm{O}+\mathrm{OH} \rightarrow \mathrm{HCO}+\mathrm{H}_{2} \mathrm{O}
$$




\begin{tabular}{|c|c|c|c|c|c|c|c|c|c|}
\cline { 2 - 10 } \multicolumn{1}{c|}{} & \multicolumn{3}{c|}{ LLNL detailed } & \multicolumn{3}{c|}{ Yao's } & \multicolumn{3}{c|}{ Wang's } \\
\cline { 2 - 10 } \multicolumn{1}{c|}{} & $\mathbf{A}$ & $\mathbf{n}$ & $\mathbf{E a}$ & $\mathbf{A}$ & $\mathbf{n}$ & $\mathbf{E a}$ & $\mathbf{A}$ & $\mathbf{n}$ & Ea \\
\hline R1 & $1.475 \mathrm{E}+12$ & 0.600 & 0.000 & $5.116 \mathrm{E}+12$ & 0.440 & 0.000 & $1.475 \mathrm{E}+12$ & 0.600 & 0.000 \\
\hline R2 & $7.580 \mathrm{E}+12$ & 0.000 & $4.100 \mathrm{E}+02$ & $1.204 \mathrm{E}+10$ & 0.807 & $-7.270 \mathrm{E}+02$ & $7.580 \mathrm{E}+12$ & 0.000 & $4.100 \mathrm{E}+02$ \\
\hline R3 & $7.820 \mathrm{E}+07$ & 1.630 & $-1.055 \mathrm{E}+03$ & $3.430 \mathrm{E}+09$ & 1.180 & $-4.470 \mathrm{E}+02$ & $3.430 \mathrm{E}+09$ & 1.180 & $-4.470 \mathrm{E}+02$ \\
\hline R4 & $2.951 \mathrm{E}+14$ & 0.000 & $4.843 \mathrm{E}+04$ & $1.110 \mathrm{E}+14$ & -0.370 & 0.000 & $1.236 \mathrm{E}+14$ & -0.370 & 0.000 \\
\hline R5 & $1.030 \mathrm{E}+14$ & 0.000 & $1.104 \mathrm{E}+04$ & $3.658 \mathrm{E}+14$ & 0.000 & $1.200 \mathrm{E}+04$ & $1.300 \mathrm{E}+11$ & 0.000 & $-1.629 \mathrm{E}+03$ \\
\hline R6 & $1.000 \mathrm{E}+12$ & 0.269 & $-6.875 \mathrm{E}+02$ & $1.340 \mathrm{E}+13$ & 0.000 & 0.000 & $2.200 \mathrm{E}+13$ & 0.000 & 0.000 \\
\hline R7 & $1.973 \mathrm{E}+10$ & 0.962 & $-3.284 \mathrm{E}+02$ & $2.891 \mathrm{E}+13$ & 0.000 & $-5.019 \mathrm{E}+02$ & $2.891 \mathrm{E}+12$ & 0.000 & $-5.019 \mathrm{E}+02$ \\
\hline
\end{tabular}

Table 6: Pre-exponential factor, $A$, temperature index, $n$ and activation energy, $E a$, for the Arrhenius definition of the specific reaction rate for the reactions and mechanisms involved in this analysis.

The generation rate of $\mathrm{HCO}$ is higher in Yao's and Wang's mechanisms because the specific reaction rate of $\mathrm{R} 3$ is enhanced compared to the detailed mechanism (Table 6). Thus, higher HCO generation implies higher relevance of R2, leading to a faster accumulation of $\mathrm{HO}_{2}$ and earlier cool flames. Moreover, the specific reaction rates of R2 and R1 are also enhanced in Yao's, causing that the ignition delay referred to cool flames occurs even earlier in such mechanism.

In Fig. 9, right, it can be seen that whereas Cai's and Yao's mechanisms under-predict the ignition delays referred to the high-temperature stage compared to the LLNL detailed mechanism, Wang's mechanisms trend to overpredict this ignition event. Regarding Cai's mechanism, these phenomena are caused by the sooner cool flames in which a certain amount of heat is released, implying a higher temperature trace that leads to shorter ignition delays referred to the high-temperature stage. As for Yao's and Wang's mechanisms, these phenomena are caused by the shorter and larger time in- 
tervals between cool flames and the high-temperature stage, $t_{i, 2-1}=t_{i, 2}-t_{i, 1}$, of Yao's and Wang's, respectively. The beginning of the high-temperature stage is controlled by the third body reaction:

$$
\mathrm{H}_{2} \mathrm{O}_{2}+\mathrm{M} \rightarrow 2 \mathrm{OH}+\mathrm{M}
$$

Thus, the high-temperature ignition stage is promoted by the $\mathrm{H}_{2} \mathrm{O}_{2}$ decomposition, which is triggered by a critical concentration of such species. Consequently, the differences between mechanisms according to the hightemperature stage can be explained by tracing the chemical kinetics of $\mathrm{H}_{2} \mathrm{O}_{2}$.

The main accumulation reaction of $\mathrm{H}_{2} \mathrm{O}_{2}$ in all the tested mechanisms is:

$$
2 \mathrm{HO}_{2} \rightarrow \mathrm{H}_{2} \mathrm{O}_{2}+\mathrm{O}_{2}
$$

On the one hand, it has been checked that the specific reaction rate of $\mathrm{R} 5$ is highly enhanced in Yao's mechanism (Table 6), in which the generation of $\mathrm{HO}_{2}$ is also faster than in the detailed mechanism, leading to a much faster accumulation of $\mathrm{H}_{2} \mathrm{O}_{2}$. Therefore, shorter ignition delays referred to the high-temperature stage are obtained by using Yao's mechanism, since the critical concentration that triggers the ignition event is reached faster.

On the other hand, the following alternative relevant decomposition path for $\mathrm{HO}_{2}$ is presented in Wang's mechanism:

$$
\mathrm{CH}_{3}+\mathrm{HO}_{2} \rightarrow \mathrm{CH}_{3} \mathrm{O}+\mathrm{OH}
$$

which is dominant enough to cause a competence with R5, leading to longer time intervals between cool flames and the high-temperature stage and, therefore, over-predicted ignition delays referred to the high-temperature stage. 
Finally, Fig. 10 shows the percentage of heat released during cool flames with respect to the total amount of heat, $Q_{\text {cool_flames }} / Q_{\text {released }}$, for all the reduced mechanisms versus the corresponding value for the detailed mechanism. It can be seen that while Yao's mechanism tends to highly over-predict the heat referred to cool flames, both Cai's and Wang's mechanisms trend to under-estimate this amount of energy.

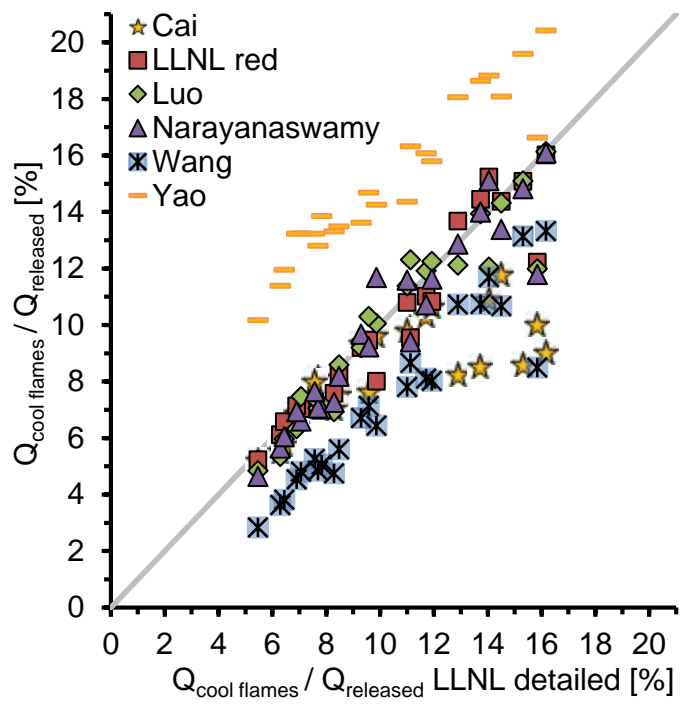

Figure 10: Percent of heat released during cool flames with respect to the total amount of heat, $Q_{\text {cool_flames }} / Q_{\text {released }}$, for all the reduced mechanisms versus the corresponding value for the detailed mechanism.

The main exothermic reaction during cool flames is:

$$
\mathrm{HO}_{2}+\mathrm{OH} \rightarrow \mathrm{H}_{2} \mathrm{O}+\mathrm{O}_{2}
$$

On the one hand, the specific reaction rate of $\mathrm{R} 7$ is highly enhanced in Yao's mechanism (Table 6), in which the generation of $\mathrm{HO}_{2}$ is also faster than in the 
LLNL detailed one, causing a higher relevance of R7 and leading to a more exothermic behavior during cool flames. On the other hand, R6, which is not as exothermic as R7, competes with $\mathrm{R} 7$ in the consumption of $\mathrm{HO}_{2}$ in Wang's mechanism, leading to lower amount of heat released in the cool flames. Finally, since cool flames occur at lower temperatures in Cai's mechanism (because of the shorter ignition delays), the highly exothermic reactions that generate intermediate products, such as reaction R7, are less relevant than for LLNL detailed mechanism, leading to lower $\mathrm{H}_{2} \mathrm{O}$ concentrations during cool flames and, therefore, to lower values of the $Q_{\text {cool_flames }} / Q_{\text {released }}$ ratio.

\section{Conclusions}

Seven chemical kinetic mechanisms, two detailed and five reduced, have been evaluated for n-dodecane versus experimental results obtained from a RCEM under ECN conditions. The experimental trends of the measured ignition delay have been explained, resulting in an absence of NTC behavior due to compensating pressure effects. Besides, the accuracy of the different mechanisms have been evaluated in a quantitative way by means of the relative deviation between simulated and measured ignition delay. Finally, a chemical kinetics analysis of the differences between mechanisms have been performed, concluding that the skeletal mechanisms that proceed from alternative detailed mechanisms are not consistent with the detailed mechanism evaluated in this work.

The following conclusions can be deduced from this study:

- A wide database of ignition delays under transient thermodynamic conditions for n-dodecane has been generated. This fuel does not show 
NTC behavior under the evaluated conditions because of pressure effects, since the higher the temperature, the higher the pressure in order to keep a constant density at TDC.

- Discarding the additional deviation caused by the emissions, combustion and other physical models, the chemical kinetic mechanisms evaluated in this investigation have an acceptable performance for engine simulations in terms of engine efficiency and fuel consumption. However, the ignition delay deviations in CAD seems to be too high to accurately predict pollutant emissions. Finally, it should be noted that the coefficient of variation between mechanisms is around $5 \%$, which implies distinguishable results but that is negligible in terms of engine simulations.

- The relative deviation between simulated and measured ignition delays shows that, in general, the high-temperature stage can be better predicted than cool flames, probably because of an incomplete description of the chemical paths at low-temperatures. However, Cai's mechanism, which includes some improvements for the low-temperature chain branching mechanism, is able to better predict cool flames than the high-temperature ignition delay. The average deviations among all the mechanisms are lower than 3.8 CAD and 4.7 CAD for cool flames and for the high temperature stage, respectively.

- The chemical analysis shows three different results. First, Yao's mechanism seems to be enhanced, leading to shorter ignition delays, shorter time gaps between cool flames and the high-temperature ignition and 
more exothermic cool flames then the LLNL detailed mechanism. These facts can be caused by the modifications for the specific reaction rates of the semi-global reactions that describe the low-temperature chemical paths. Secondly, Wang's mechanism is based on an older detailed mechanisms, leading to inconsistent results compared to the LLNL detailed one. Shorter ignition delays referred to cool flames but longer time gaps between cool flames and the high-temperature ignition and, therefore, high-temperature ignition delays are reached, as well as less exothermic cool flames. Finally, Cai's mechanism includes additional reaction pathways and improved specific reaction rates for the low-temperature mechanism, which lead to shorter ignition delays referred to cool flames and, consequently, slightly shorter ignition delays referred to the hightemperature stage. Moreover, less exothermic cool flames are obtained, since the ignition occurs at lower temperatures (shorter ignition times). 
$B D C$

$C F D$

$C R$

Da

$D R G$

${ }^{712}$ DRGASA

$D R G-X$

Ea

$E C N$

EGR

$\mathrm{Fr}$

$L L N L$
Pre-exponential factor for the Arrhenius expression

Bottom Dead Center

Computational Fluid Dynamics

Compression Ratio

Damköhler number

Directed Relation Graph

Directed Relation Graph combined with sensitivity analysis

Directed Relation Graph with expert knowledge

Activation energy for the Arrhenius expression

Engine Combustion Network

Exhaust Gas Recirculation

Working equivalence ratio

Lawrence Livermore National Laboratory 
$n$

NTC

$P$

$P_{i}$

$P A H$

$Q_{\text {cool_flames }} / Q_{\text {released }}$

$R^{2}$

$R C E M$

$T_{i}$

$T D C$

$t_{i, 1}$

$t_{i, 2}$

$t_{i, 2-1}$

$X_{O 2}$

$\epsilon$

$|\bar{\epsilon}|$

$\tau$
Temperature index for the Arrhenius expression

Negative Temperature Coefficient

Pressure

Initial pressure

Polycyclic Aromatic Hydrocarbons

Percent of heat released during cool flames with respect to the total amount of heat

Pearson's coefficient of correlation

Rapid Compression-Expansion Machine

Initial temperature

Top Dead Center

Ignition delay referred to cool flames

Ignition delay referred to the high-temperature stage of the process

Time interval between cool flames and the high-temperature ignition stage

Oxygen molar fraction

Percentage deviation in ignition delay between experimental and simulation results

Mean absolute deviation between experimental and simulation results

Ignition delay under constant conditions of pressure and temperature 


\section{Appendix A. Autoignition thermodynamic conditions}

The in-cylinder thermodynamic conditions at the ignition point are summarized in Tables A.7 and A.8 for cool flames and for the high-temperature stage, respectively. The ignition delay referred to cool flames and to the hightemperature stage of all cases are also shown. The coefficient of variation, $C V$, has been calculated for each parameter and its result is also shown in the table.

Under transient thermodynamic conditions, the ignition delay depends on the in-cylinder temperature and pressure paths. Therefore, the ignition conditions does not provide information enough to study the ignition delay behavior. In fact, under engine conditions and by keeping constant the compression ratio, the initial temperature and pressure or the thermodynamic conditions at TDC are good parameters to characterize the in-cylinder conditions and, therefore, to analyze the ignition delay behavior. However, the autoignition conditions are useful to compare the ignition delay under engine conditions to the ignition delay under constant conditions measured in shock-tube experiments. 


\begin{tabular}{|c|c|c|c|c|c|c|c|c|c|}
\hline$X_{O_{2}}[-]$ & $T_{T D C}[K]$ & $P_{T D C}[b a r]$ & $\operatorname{Fr}[-]$ & $t_{i, 1}[m s]$ & $C V$ & $T_{t_{i, 1}}[K]$ & $C V$ & $P_{t i, 1}[$ bar $]$ & $C V$ \\
\hline \multirow{12}{*}{0.21} & \multirow{3}{*}{1000} & \multirow{3}{*}{67.47} & 0.8 & 1.070 & 1.795 & 764.45 & 1.983 & 19.14 & 2.947 \\
\hline & & & 0.9 & 1.121 & 0.769 & 771.26 & 1.180 & 19.94 & 1.336 \\
\hline & & & 1 & 1.110 & 1.533 & 764.04 & 1.217 & 19.09 & 0.857 \\
\hline & \multirow{3}{*}{950} & \multirow{3}{*}{64.10} & 0.8 & 1.408 & 0.763 & 768.65 & 1.141 & 22.86 & 1.112 \\
\hline & & & 0.9 & 1.457 & 1.073 & 772.36 & 0.309 & 23.84 & 0.855 \\
\hline & & & 1 & 1.404 & 0.685 & 768.21 & 0.307 & 22.80 & 0.844 \\
\hline & \multirow{3}{*}{900} & \multirow{3}{*}{60.09} & 0.8 & 1.763 & 1.316 & 714.08 & 0.289 & 19.53 & 0.487 \\
\hline & & & 0.9 & 1.779 & 1.146 & 726.04 & 0.433 & 21.10 & 0.514 \\
\hline & & & 1 & 1.780 & 0.544 & 726.98 & 0.302 & 21.23 & 0.244 \\
\hline & \multirow{3}{*}{850} & \multirow{3}{*}{53.90} & 0.8 & 2.404 & 1.520 & 715.82 & 0.734 & 21.92 & 2.232 \\
\hline & & & 0.9 & 2.199 & 0.765 & 694.94 & 0.238 & 19.01 & 0.143 \\
\hline & & & 1 & 2.209 & 0.512 & 699.30 & 0.169 & 19.59 & 0.459 \\
\hline \multirow{12}{*}{0.15} & \multirow{3}{*}{1000} & \multirow{3}{*}{67.47} & 0.8 & 1.271 & 2.086 & 774.02 & 2.779 & 20.28 & 2.172 \\
\hline & & & 0.9 & 1.268 & 1.610 & $773 . .88$ & 1.622 & 20.26 & 1.659 \\
\hline & & & 1 & 1.276 & 1.177 & 774.59 & 0.845 & 20.35 & 1.089 \\
\hline & \multirow{3}{*}{950} & \multirow{3}{*}{64.10} & 0.8 & 1.521 & 2.057 & 768.79 & 1.814 & 22.88 & 1.402 \\
\hline & & & 0.9 & 1.577 & 1.518 & 772.85 & 1.418 & 23.92 & 0.848 \\
\hline & & & 1 & 1.568 & 1.724 & 771.43 & 0.726 & 23.24 & 1.266 \\
\hline & \multirow{3}{*}{900} & \multirow{3}{*}{60.69} & 0.8 & 1.850 & 0.292 & 744.92 & 2.189 & 23.78 & 1.630 \\
\hline & & & 0.9 & 1.872 & 1.719 & 746.50 & 0.924 & 24.02 & 0.206 \\
\hline & & & 1 & 1.856 & 0.767 & 745.21 & 0.530 & 23.82 & 0.530 \\
\hline & \multirow{3}{*}{850} & \multirow{3}{*}{53.90} & 0.8 & 2.504 & 2.012 & 750.07 & 1.509 & 29.69 & 2.488 \\
\hline & & & 0.9 & 2.386 & 1.963 & 758.70 & 0.688 & 31.38 & 0.472 \\
\hline & & & 1 & 2.361 & 1.565 & 760.72 & 0.470 & 31.78 & 0.745 \\
\hline
\end{tabular}

Table A.7: Ignition delay and thermodynamic conditions of ignition referred to cool flames for all cases. The coefficient of variation, $C V$, of each parameter is also shown. 


\begin{tabular}{|c|c|c|c|c|c|c|c|c|c|}
\hline$X_{\mathrm{O}_{2}}[-]$ & $T_{T D C}[K]$ & $P_{T D C}[$ bar $]$ & $\operatorname{Fr}[-]$ & $t_{i, 2}[\mathrm{~ms}]$ & $C V$ & $T_{t_{i, 2}}[K]$ & $C V$ & $P_{t i, 2}[$ bar $]$ & $C V$ \\
\hline \multirow{12}{*}{0.21} & \multirow{3}{*}{1000} & \multirow{3}{*}{67.47} & 0.8 & 1.221 & 1.775 & 803.58 & 3.670 & 24.13 & 3.033 \\
\hline & & & 0.9 & 1.216 & 0.095 & 800.49 & 0.718 & 23.70 & 2.527 \\
\hline & & & 1 & 1.302 & 1.332 & 805.74 & 1.719 & 24.43 & 1.720 \\
\hline & \multirow{3}{*}{950} & \multirow{3}{*}{64.10} & 0.8 & 1.565 & 1.831 & 807.37 & 0.743 & 28.66 & 0.816 \\
\hline & & & 0.9 & 1.617 & 0.898 & 808.03 & 0.265 & 28.70 & 1.568 \\
\hline & & & 1 & 1.672 & 1.899 & 808.27 & 2.565 & 28.80 & 0.284 \\
\hline & \multirow{3}{*}{900} & \multirow{3}{*}{60.09} & 0.8 & 1.955 & 0.816 & 758.59 & 0.429 & 25.33 & 1.609 \\
\hline & & & 0.9 & 1.980 & 1.767 & 761.13 & 0.853 & 26.31 & 0.450 \\
\hline & & & 1 & 1.957 & 0.362 & 760.08 & 0.785 & 26.23 & 0.379 \\
\hline & \multirow{3}{*}{850} & \multirow{3}{*}{53.90} & 0.8 & 2.590 & 1.764 & 764.22 & 0.626 & 32.49 & 2.714 \\
\hline & & & 0.9 & 2.580 & 0.842 & 759.72 & 0.223 & 31.58 & 0.848 \\
\hline & & & 1 & 2.505 & 1.202 & 756.55 & 0.189 & 30.95 & 0.301 \\
\hline \multirow{12}{*}{0.15} & \multirow{3}{*}{1000} & \multirow{3}{*}{67.47} & 0.8 & 1.713 & 1.238 & 839.71 & 2.301 & 29.60 & 2.240 \\
\hline & & & 0.9 & 1.615 & 1.043 & 824.60 & 1.297 & 27.20 & 1.632 \\
\hline & & & 1 & 1.526 & 1.393 & 820.03 & 1.985 & 26.51 & 1.737 \\
\hline & \multirow{3}{*}{950} & \multirow{3}{*}{64.10} & 0.8 & 2.022 & 2.073 & 840.10 & 1.979 & 34.45 & 2.007 \\
\hline & & & 0.9 & 1.960 & 1.267 & 831.43 & 1.420 & 32.76 & 0.996 \\
\hline & & & 1 & 1.891 & 0.786 & 821.70 & 0.835 & 31.08 & 0.927 \\
\hline & \multirow{3}{*}{900} & \multirow{3}{*}{60.69} & 0.8 & 2.443 & 2.019 & 816.20 & 1.198 & 36.58 & 2.196 \\
\hline & & & 0.9 & 2.364 & 0.512 & 810.82 & 0.509 & 35.45 & 0.616 \\
\hline & & & 1 & 2.305 & 0.218 & 796.24 & 0.529 & 32.53 & 0.347 \\
\hline & \multirow{3}{*}{850} & \multirow{3}{*}{53.90} & 0.8 & 3.034 & 2.038 & 775.14 & 1.703 & 32.73 & 1.997 \\
\hline & & & 0.9 & 2.880 & 0.489 & 759.00 & 0.626 & 29.35 & 0.682 \\
\hline & & & 1 & 2.806 & 1.011 & 753.75 & 0.255 & 28.33 & 1.240 \\
\hline
\end{tabular}

Table A.8: Ignition delay and thermodynamic conditions of ignition referred to the hightemperature stage for all cases. The coefficient of variation, $C V$, of each parameter is also shown. 


\section{References}

[1] L.M. Pickett, C.L. Genzale, G. Bruneaux, L.M. Malbec, L. Hermant, C. Christiansen, and J. Schramm. Comparison of diesel spray combustion in different high-temperature, high-pressure facilities. SAE Technical Paper, 2010-01-2106, 2010.

[2] L.M. Malbec, J. Egúsquiza, G. Bruneaux, and M. Meijer. Characterization of a set of ecn spray a injectors: Nozzle to nozzle variations and effect on spray characteristics. SAE Technical Paper, 2013-24-0037, 2013.

[3] Y. Pei, E.R. Hawkes, S. Kook, G.M. Goldin, and T. Lu. Modelling ndodecane spray and combustion with the transported probability density function method. Combustion and Flame, 162:2006-2019, 2015.

[4] R. Novella, A. García, J.M. Pastor, and V. Domenech. The role of detailed chemical kinetics on cfd diesel spray ignition and combustion modelling. Mathematical and Computer Modelling, 54:1706-1719, 2011.

[5] E. Hawkes. Ecn 4 - topic 4: Chemistry effects on ignition (in spray a). Fourth Workshop of the Engine Combustion Network (www.sandia.gov/ecn), 2015.

[6] Perrine Pepiot and Heinz Pitsch. Systematic reduction of large chemical mechanisms. 4th Joint Meeting of the U.S. Sections of the Combustion Institute, 2005.

[7] S. Vajda, P. Valko, and T. Turányi. Principal component analysis of 
kinetic models. International Journal of Chemical Kinetics, 17:55-81, 1985.

[8] T. Turányi. Sensitivity analysis of complex kinetic systems. tools and applications. Journal of Mathematical Chemistry, 5:203-248, 1990.

[9] T. Turányi. Reduction of large reaction mechanisms. New Journal of Chemistry, 14:795-803, 1990.

[10] H. Wang and M. Frenklach. Detailed reduction of reaction mechanisms for flame modeling. Combustion and Flame, 87:365-370, 1991.

[11] T. Lu and C.K. Law. Linear time reduction of large kinetic mechanisms with directed relation graph: n-heptane and iso-octane. Combustion and Flame, 144:24-36, 2006.

[12] Z. Chen W. Sun and, X. Gou, and Y. Ju. A path flux analysis method for the reduction of detailed chemical kinetic mechanisms. Combustion and Flame, 157:1298-1307, 2010.

[13] S.M. Sarathy, C.K. Westbrook, M. Mehl, W.J. Pitz, C. Togbe, P. Dagaut, H. Wang, M.A. Oehlschlaeger, U. Niemann, K. Seshadri, P.S. Veloo, C. Ji, F.N. Egolfopoulos, and T. Lu. Comprehensive chemical kinetic modeling of the oxidation of 2-methylalkanes from c7 to c20. Combustion and Flame, 158:2338-2357, 2011.

[14] T. Lu, M. Plomer, Z. Luo, S.M. Sarathy, W.J. Pitz, S. Som, and D.E. Longman. Directed relation graph with expert knowledge for skeletal mechanism reduction. 7th US National Combustion Meeting, Paper 1A03,:203-248, 2011. 
[15] Z. Luo, S. Som, S. M. Sarathy, M. Plomer, W. J. Pitz, D. E. Longman, and T. Lu. Development and validation of an n-dodecane skeletal mechanism for spray combustion applications. Combustion Theory and Modelling, 18:187-203, 2014.

[16] K. Narayanaswamy, P. Pepiot, and H. Pitsch. A chemical mechanism for low to high temperature oxidation of n-dodecane as a component of transportation fuel surrogates. Combustion and Flame, 161:866-884, 2014 .

[17] G. Blanquart, P. Pepiot-Desjardins, and H. Pitsch. Chemical mechanism for high temperature combustion of engine relevant fuels with emphasis on soot precursors. Combustion and Flame, 156:588-607, 2009.

[18] K. Narayanaswamy, G. Blanquart, and H. Pitsch. A consistent chemical mechanism for the oxidation of substituted aromatic species. Combustion and Flame, 157:1879-1898, 2010.

[19] H. Wang, Y. Ra, M. Jia, and R.D. Reitz. Development of a reduced n-dodecane-pah mechanism and its application for n-dodecane soot predictions. Fuel, 136:25-36, 2014.

[20] C.K. Westbrook, W.J. Pitz, O. Herbinet, H.J. Curran, and E.J. Silke. A detailed chemical kinetic reaction mechanism for n-alkane hydrocarbons from n-octane to n-hexadecane. Combustion and Flame, 156:181-199, 2009.

[21] H. Wang, R.D. Reitz, M. Yao, B. Yang, Q. Jiao, and L. Qiu. Development of an n-heptane-n-butanol-pah mechanism and its application for 
combustion and soot prediction. Combustion and Flame, 160:504-519, 2013.

[22] T. Yao, Y. Pei, B.J. Zhong, S. Som, and T. Lu. A hybrid mechanism for n-dodecane combustion with optimized low-temperature chemistry. 9th US National Combustion Meeting, 2015.

[23] X. You, F.N. Egolfopoulos, and H. Wang. Detailed and simplified kinetic models of n-dodecane oxidation: The role of fuel cracking in aliphatic hydrocarbon combustion. Proceedings of the Combustion Institute, 32:403410, 2009.

[24] San Diego Mechanism web page. Chemical-kinetic mechanisms for combustion applications. Mechanical and Aerospace Engineering (Combustion Research), University of California at San Diego (http://combustion.ucsd.edu), 2016.

[25] G. Bikas and N. Peters. Kinetic modelling of n-decane combustion and autoignition: Modeling combustion of n-decanem. Combustion and Flame, 126:1456-1475, 2001.

[26] L. Cai, H. Pitsch, S.Y. Mohamed, V. Raman, J. Bugler, H. Curran, and S.M. Sarathy. Optimized reaction mechanism rate rules for ignition of normal alkanes. Combustion and Flame, 173:468-482, 2016.

[27] J. Bugler, K.P. Somers, E.J. Silke, and H.J. Curran. Revisiting the kinetics and thermodynamics of the low-temperature oxidation pathways of alkanes: A case study of the three pentane isomers. The Journal of Physical Chemistry, 119:7510-7527, 2015. 
[28] R. Sivaramakrishnan and J.V. Michael. Rate constants for oh with selected large alkanes: shock-tube measurements and an improved group scheme. The Journal of Physical Chemistry, 113:5047-5060, 2009.

[29] U. Pfahl, K. Fieweger, and G. Adomeit. Self-ignition of diesel-relevant hydrocarbon-air mixtures under engine conditions. Twenty-Sixth Symposium (International) on Combustion/The Combustion Institute, pages 781-789, 1996.

[30] H.P.S. Shen, J. Steinberg, J. Vanderover, and M.A. Oehlschlaeger. A shock tube study of the ignition of n-heptane, n-decane, n-dodecane, and n-tetradecane at elevated pressures. Energy and Fuels, 23:24822489, 2009.

[31] M. Sjöberg, J.E. Dec, and N.P. Cernansky. Potential of thermal stratification and combustion retard for reducing pressure-rise rates in HCCI engines, based on multi-zone modeling and experiments. SAE Technical Paper, 2005-01-0113, 2005.

[32] J.H. Chen, E.R. Hawkes, R. Sankaran, S.D. Mason, and H.G. Im. Direct numerical simulation of ignition front propagation in a constant volume with temperature inhomogeneities I. fundamental analysis and diagnostics. Combustion and Flame, 145:128-144, 2006.

[33] C.S. Yoo, T. Lu, J.H. Chen, and C.K. Law. Direct numerical simulations of ignition of a lean n-heptane/air mixture with temperature inhomogeneities at constant volume: Parametric study. Combustion and Flame, 158:1727-1741, 2011. 
[34] J. M. Desantes, J.M. García-Oliver, W. Vera-Tudela, D. López-Pintor, B. Schneider, and K. Boulouchos. Study of ignition delay time and generalization of auto-ignition for PRFs in a RCEM by means of natural chemiluminescence. Energy Conversion and Management, 111:217-228, 2016.

[35] J. M. Desantes, J. J. López, S. Molina, and D. López-Pintor. Theoretical development of a new procedure to predict ignition delays under transient thermodynamic conditions and validation using a Rapid Compression-Expansion Machine. Energy Conversion and Management, 108:132-143, 2016.

[36] J. M. Desantes, , V. Bermúdez, J. J. López, and D. López-Pintor. A new method to predict high and low-temperature ignition delays under transient thermodynamic conditions and its experimental validation using a Rapid Compression-Expansion Machine. Energy Conversion and Management, 123:512-522, 2016.

[37] J.M. Desantes, J.J. López, J.M. García-Oliver, and D. López-Pintor. A 5-zone model to improve the diagnosis capabilities of a Rapid Compression-Expansion Machine (RCEM) in autoignition studies. SAE World Congress, under revision, 2017.

[38] R. Payri, F.J. Salvador, J. Gimeno, and G. Bracho. A new methodology for correcting the signal cumulative phenomenon on injection rate measurements. Experimental Techniques, 32:46-49, 2008.

[39] J.C. Livengood and P.C. Wu. Correlation of autoignition phenomena in 
internal combustion engines and rapid compression machines. Symposium (International) on Combustion, 5:347-356, 1955.

[40] J. Benajes, P. Olmeda, J. Martín, and R. Carreño. A new methodology for uncertainties characterization in combustion diagnosis and thermodynamic modelling. Applied Thermal Engineering, 71:389-399, 2014.

[41] F. Payri, S. Molina, J. Martín, and O. Armas. Influence of measurement errors and estimated parameters on combustion diagnosis. Applied Thermal Engineering, 26:226-236, 2006.

[42] G. Woschni. A universally applicable equation for the instantaneous heat transfer coefficient in the internal combustion engine. SAE Paper no. 670931, 1967.

[43] K. Kumar, G. Mittal, and C.J. Sung. Autoignition of n-decane under elevated pressure and low-to-intermediate temperature conditions. Combustion and Flame, 156:1278-1288, 2009.

[44] A. Martell. Oxygen complexes and oxygen activation by transition metals. Springer, 1988. 